\title{
GSK3 $\beta$ regulates physiological migration of stem/progenitor cells via cytoskeletal rearrangement
}

\author{
Kfir Lapid,1 Tomer Itkin, ${ }^{1}$ Gabriele D’Uva, ${ }^{1}$ Yossi Ovadya, ${ }^{1}$ Aya Ludin, ${ }^{1}$ Giulia Caglio, ${ }^{1}$ \\ Alexander Kalinkovich,, ${ }^{1}$ Karin Golan, ${ }^{1}$ Ziv Porat, ${ }^{2}$ Massimo Zollo, ${ }^{3}$ and Tsvee Lapidot ${ }^{1}$ \\ ${ }^{1}$ Department of Immunology and 2 Flow Cytometry Unit, Department of Biological Services, Weizmann Institute of Science, Rehovot, Israel. \\ ${ }^{3}$ Faculty of Biotechnological Sciences, University Federico II, Naples, Italy.
}

\begin{abstract}
Regulation of hematopoietic stem and progenitor cell (HSPC) steady-state egress from the bone marrow (BM) to the circulation is poorly understood. While glycogen synthase kinase-3 $\beta$ (GSK3 $\beta$ ) is known to participate in HSPC proliferation, we revealed an unexpected role in the preferential regulation of CXCL12-induced migration and steady-state egress of murine HSPCs, including long-term repopulating HSCs, over mature leukocytes. HSPC egress, regulated by circadian rhythms of CXCL12 and CXCR4 levels, correlated with dynamic expression of GSK3 $\beta$ in the BM. Nevertheless, GSK3 $\beta$ signaling was CXCL12/CXCR4 independent, suggesting that synchronization of both pathways is required for HSPC motility. Chemotaxis of HSPCs expressing higher levels of GSK $3 \beta$ compared with mature cells was selectively enhanced by stem cell factor-induced activation of GSK3 $\beta$. Moreover, HSPC motility was regulated by norepinephrine and insulin-like growth factor-1 (IGF-1), which increased or reduced, respectively, GSK3 $\beta$ expression in BM HSPCs and their subsequent egress. Mechanistically, GSK3 $\beta$ signaling promoted preferential HSPC migration by regulating actin rearrangement and microtubuli turnover, including CXCL12-induced actin polarization and polymerization. Our study identifies a previously unknown role for GSK3 $\beta$ in physiological HSPC motility, dictating an active, rather than a passive, nature for homeostatic egress from the $\mathrm{BM}$ reservoir to the blood circulation.
\end{abstract}

\section{Introduction}

Apart from self-renewal, another hallmark of hematopoietic stem cells (HSCs) is their motility, characterized by the ability to migrate in response to chemotactic cues and to be recruited to target tissues, where they undergo proliferation and differentiation upon demand (1). In a steady state, low levels of HSPCs are constantly circulating as part of homeostasis, whereas in stress situations, HSPCs are recruited in high numbers from the bone marrow (BM) into the circulation as part of host defense and repair mechanisms (2). Glycogen synthase kinase- $3 \beta$ (GSK3 $\beta$ ) is a well-established negative regulator of the Wnt $/ \beta$-catenin pathway, implicated in self-renewal and development of human and murine HSCs (3-11). In addition to proliferation, GSK3 $\beta$ has been shown to be involved in the motility of various cells, including microglia, epidermal stem cells, human mast cells, and breast cancer cells (12-16), but its effect on the motility of immature hematopoietic cells has not been addressed. On the other hand, the chemokine CXCL12 (also termed stromal-derived factor-1, referred to herein as SDF-1) and its major receptor CXCR4 have well-characterized roles in directional motility and quiescence of human and murine HSPCs (17-20). Of note, the migratory potential of human CD $34^{+}$HSPCs toward a gradient of CXCL12 in vitro correlates with the hematopoietic recovery following clinical autologous transplantations (21). Furthermore, it has been demonstrated that day and night circadian fluctuations in circulating murine HSPCs reversely correlate with oscillations of CXCL12 levels in the BM, both of which are controlled by the sympathetic nervous system (22). We hypothesize that physiolog-

Conflict of interest: The authors have declared that no conflict of interest exists. Citation for this article: J Clin Invest. 2013;123(4):1705-1717. doi:10.1172/JCI64149. ical egress of HSPCs is regulated by cell-intrinsic mechanisms of migration that require cooperation with extrinsic factors, such as CXCL12 and norepinephrine (NE). Rapid mobilization of HSPCs is observed following administration of AMD3100, which competes with CXCL12 binding to CXCR4, or in vivo stimulation of adrenergic receptors with $\mathrm{NE}(23,24)$. Catecholamines by themselves directly augment the motility of human HSPCs (25). Interestingly, cKit (also termed CD117), which serves as a marker for HSPCs, and its ligand SCF (also termed Kit ligand), are involved in human and murine HSPC motility (26-30), pointing to a signaling pathway that uniquely regulates the migration of immature hematopoietic cells over mature leukocytes. Moreover, mutant mice with low serum levels of IGF-1 exhibit markedly increased numbers of circulating HSPCs with normal numbers of mature white blood cells (WBCs) (31), pointing to another mechanism by which the egress of immature hematopoietic cells is preferentially regulated. Since SCF and IGF-1 are involved in HSPC self-renewal and proliferation (32-35), as GSK3 $\beta$ is, we wondered whether they also regulate HSPC motility via GSK3 $\beta$. All the mechanisms by which a cell moves involve control over its cytoskeletal dynamics. CXCL12 stimulation has been shown to induce actin polymerization and cell polarization in HSPCs within minutes (36), and it triggers various signaling pathways that are involved in cytoskeletal rearrangement $(37,38)$. Turnover of the microtubuli (MT) network is also essential for the directional migration of HSPCs (39). In this study, we revealed an unexpected role of GSK $3 \beta$ signaling in preferentially promoting directional murine HSPC migration via actin and MT rearrangement. GSK3 $\beta$ activity was not directly triggered by the CXCL12/ CXCR4 axis, but rather the synchronization of both was required for directional HSPC migration. Strikingly, we found that GSK3 $\beta$ 
expression in BM HSPCs and the correspondingly physiological egress rates of HSPCs were regulated by circadian rhythms, as well as by NE stimulation and IGF-1 and SCF/cKit signaling. Additionally, we demonstrate that the egress of long-term repopulating (LTR) HSCs, which were defined by LTR assays, is also regulated by cell-autonomous GSK3 $\beta$-mediated signaling. Based on our observations, we suggest that GSK3 $\beta$ promotes steady-state egress of HSPCs from the BM reservoir to the circulation by controlling the migratory machinery.

\section{Results}

GSK3 $\beta$ expression in HSPCs correlates with their physiological egress rates and is regulated by adrenergic signals. Circulating levels of HSPCs are guided by circadian rhythms $(22,40)$. Although recent evidence suggests that circadian regulation of CXCL12 and CXCR4 levels affects the steady-state egress rates of HSPCs, we were looking for an additional signaling pathway that potentiates HSPC motility as part of this homeostatic regulation. Focusing on GSK3 $\beta$, we detected several-fold higher expression in immature hematopoietic cells, including phenotypic (CD34- $\mathrm{Lin}^{-} \mathrm{Sca}-1^{+} \mathrm{CKit}^{+}$, referred to herein as CD34-LSK) HSCs, as compared with mature $\mathrm{Lin}^{+} \mathrm{BM}$ cells (Figure 1A and Supplemental Figure 1A; supplemental material available online with this article; doi:10.1172/ JCI64149DS1). Strikingly, GSK3 $\beta$ expression in the murine BM (Figure 1B), including both the whole population and HSPCs, was found to be correlated with the circulating levels of WBCs and HSPCs (Figure 1, C and D). The highest expression of GSK3 $\beta$ was observed during the peak egress at zeitgeber time (ZT) 5 hours after initiation of light (ZT5), whereas the lowest expression of GSK3 $\beta$ was observed during the low point of egress at ZT 1 hour after initiation of darkness (ZT13) (Figure 1, B-D, and Supplemental Figure 1B). The levels of pY216-GSK3 $\beta$ (i.e., the active Tyr216-phosphorylation site) expressed in BM HSPCs correlated with the changes in total GSK3 $\beta$ levels, whereas the levels of pS9-GSK3 $\beta$ (i.e., the inactive Ser9-phosphorylation site) were unaltered (Supplemental Figure 2A), reflecting dynamic GSK3 $\beta$ activity that correlated with HSPC egress. Since circadian regulation of HSPC egress and acute recruitment of HSPCs to the circulation are controlled by signals from the sympathetic nervous system $(22,41,42)$, we examined the involvement of GSK3 $\beta$ in the mobilization induced by in vivo stimulation of $\beta 2$-adrenergic receptors. Confirming our previous data (24), the administration of NE induced mobilization of HSPCs within 1 hour (Figure 1F). Milder but significant effects were observed for circulating WBC levels (Figure 1E). In line with our hypothesis, GSK3 $\beta$ expression was preferentially elevated in BM HSPCs upon adrenergic stimulation with NE, correlating with enhanced HSPC egress (Figure $1 \mathrm{G})$. The elevation of GSK3 $\beta$ expression was higher in the more primitive cells. The expression of pY216-GSK3 $\beta$ was increased as well, while pS9-GSK3 $\beta$ expression was unaltered in BM HSPCs (Supplemental Figure 2B). Notably, these changes in GSK3 $\beta$ expression were observed as soon as 20 minutes after adrenergic stimulation with NE, but not after 1 hour, when the effect on HSPC egress is at its peak, suggesting that dynamic changes in GSK3 $\beta$ expression precede changes in HSPC egress. Furthermore, BM HSPCs that were obtained from NE-treated mice demonstrated increased in vitro migration toward CXCL12 compared with their PBS-treated counterparts (Figure 1H). Taken together, GSK3 $\beta$ expression in BM HSPCs correlated with their egress rates and directional migratory potential.
GSK3 $\beta$ is preferentially involved in HSPC motility. In order to investigate the direct effects of GSK3 $\beta$ on HSPC motility, we utilized a selective GSK3 $\beta$ inhibitor designated as BIO-A (see Methods). $\mathrm{BM}$ mononuclear cells (MNCs) were pretreated with BIO-A prior to subjecting them to in vitro migration, spontaneous migration, or migration toward CXCL12. Inhibition of GSK3 $\beta$ had no significant effect on their spontaneous or directional migration (Figure 2A). Nevertheless, since the aim is to specifically evaluate the motility of HSPCs rather than mature leukocytes, we examined the migratory capacity of HSPCs, including CFU cells, $\mathrm{Lin}^{-} \mathrm{cKit}^{+}(\mathrm{LK})$ cells, and phenotypic HSCs. Remarkably, inhibition of GSK3 $\beta$ in HSPCs selectively reduced their CXCL12-induced migration (Figure 2, B and C). Of note, we observed no motility-independent effect on the colony-forming capacity of BM cells by short pretreatment with BIO-A (data not shown), excluding the reduction in CFU cell numbers due to diminished proliferation or differentiation. Of importance, GSK3 $\beta$ was not activated in response to CXCL12, as indicated by unaltered pS9-GSK3 $\beta$ and pY216-GSK3 $\beta$ levels (Supplemental Figure 2C). In addition, CXCR4 levels were unaltered following pretreatment with BIO-A (Figure 2D), implying a CXCL12/CXCR4-independent motility mechanism for HSPCs. Next, we evaluated the effects of GSK3 $\beta$ inhibition on HSPC motility in vivo. As soon as 1 hour after administration of BIO-A, the numbers of circulating HSPCs were markedly decreased (Figure 2, F and G, and Supplemental Figure 3A), with a nonsignificant effect on circulating mature WBCs (Figure 2E). In order to rule out possible toxic or proliferative effects as the cause for the reduction in circulating HSPCs, BM HSPC levels were examined and found to be unaffected by in vivo GSK3 $\beta$ inhibition (Supplemental Figure 4, A and B). To further strengthen our hypothesis with regard to the role of GSK3 $\beta$ in physiological HSPC egress, we used LTR assays to evaluate functional LTR HSCs in the peripheral blood (PB) of mice treated or not with BIO-A. Indeed, BIO-A treatment in donor mice led to a significant decrease of approximately $80 \%$ in their circulating LTR HSCs (Figure $2 \mathrm{H}$ and Supplemental Figure 3B). Another assay by which migratory potential is evaluated in vivo is the homing assay. BM MNCs were pretreated with BIO-A prior to transplantation in lethally irradiated NOD/SCID mice. The enumeration of donor HSPCs revealed that GSK3 $\beta$ inhibition impaired their homing capacity to the $\mathrm{BM}$ in recipient mice (Figure 3A). Since GSK3 $\beta$ was found to be associated with NE-induced mobilization of HSPCs (Figure 1, E-G), mice were treated with BIO-A prior to NE stimulation, demonstrating that GSK3 $\beta$ inhibition could block NE-induced mobilization of HSPCs (Figure 3, B and C, and Supplemental Figure 3A). In conclusion, these results suggest that both GSK3 $\beta$ activity and CXCL12/CXCR4 cooperate to mediate directional HSPC motility. Moreover, this mechanism is preferentially used by immature and primitive HSPCs, over mature leukocytes, as manifested by in vitro migration, steady-state egress, rapid mobilization, and homing capacity.

IGF-1 receptor signaling regulates HSPC motility in a GSK3ß-dependent manner. We looked for a cytokine that could affect GSK3 $\beta$ activity, and since IGF-1 receptor (IGF-1R) signaling has been shown to inactivate GSK3 $\beta(43,44)$, we utilized IGF-1 administration as an approach to inactivate GSK3 $\beta$ in vivo. Confirming previous observations (34), mice treated with IGF-1 for 7 consecutive days had increased HSPC numbers in the BM and spleen compared with PBS-treated mice, without affecting cellularity in these organs (data not shown). On the contrary, we observed a decrease in the numbers of circulating WBCs and 
A
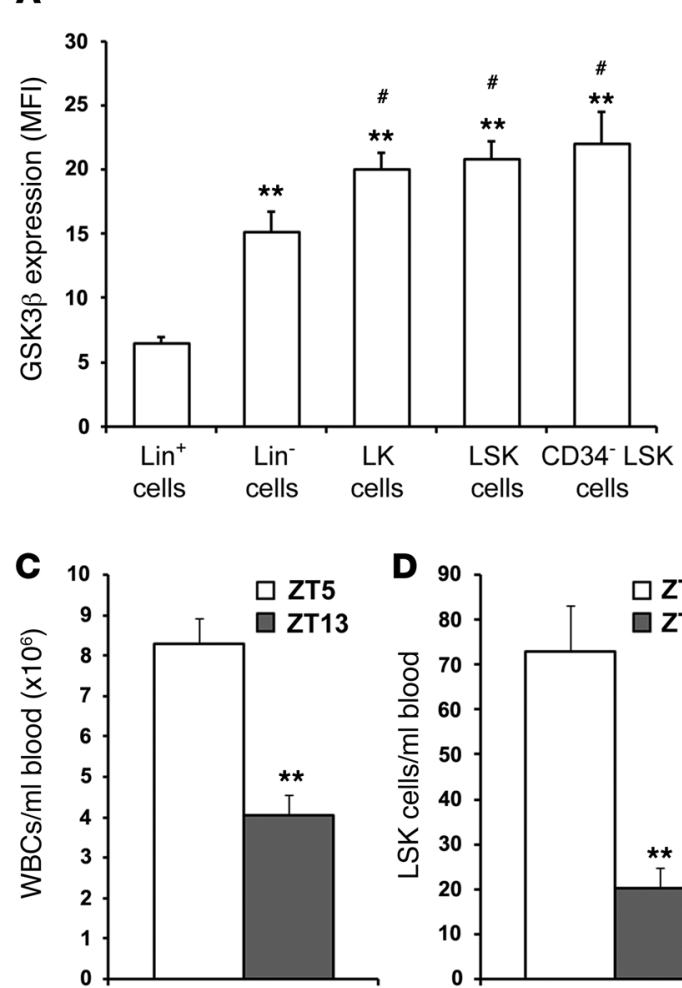

PB WBCs

G

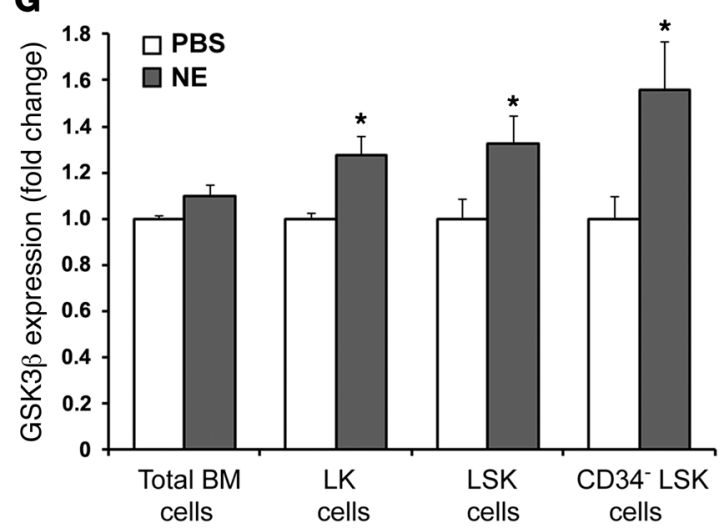

B
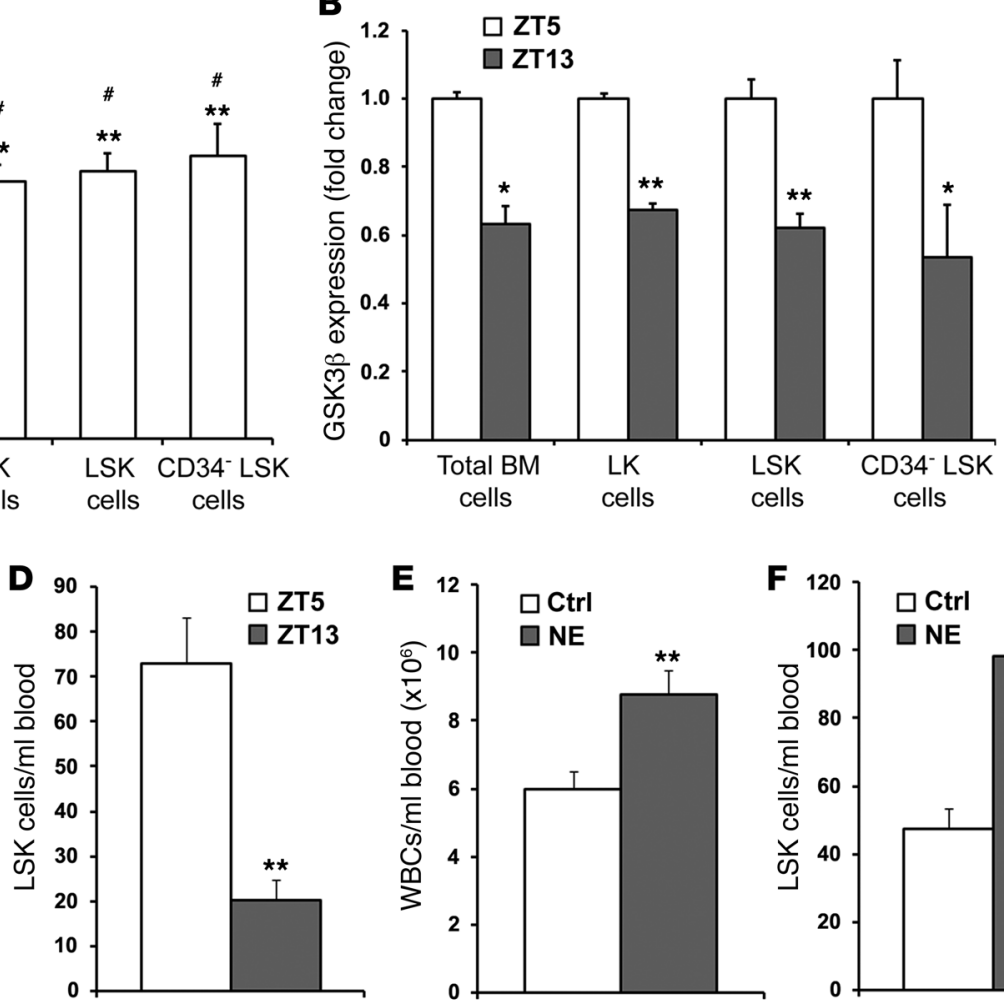

PB WBCs

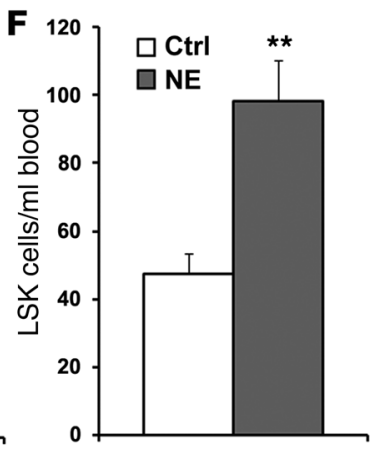

PB LSK

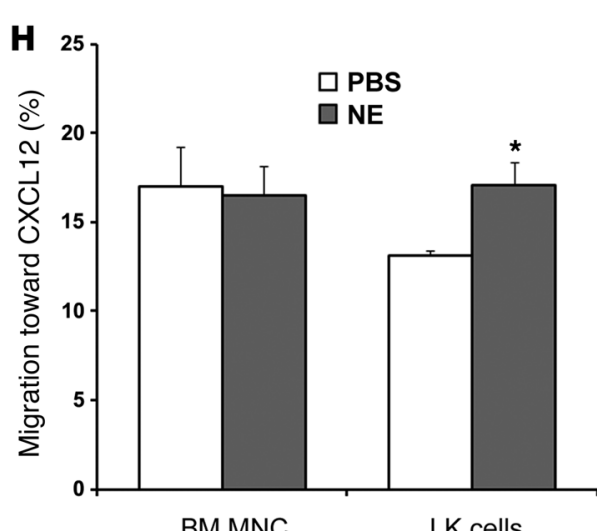

Figure 1

GSK3 $\beta$ expression in HSPCs correlates with their physiological egress rates and is regulated by adrenergic signals. (A) GSK3 $\beta$ expression levels in MFI units were compared between mature and immature BM populations: Lin+ cells, Lin- cells, $\mathrm{Lin}^{-} \mathrm{cKit}{ }^{+}$(LK) cells, Lin-Sca-1+cKit ${ }^{+}$(LSK) cells, and CD34-Lin-Sca-1+CKit ${ }^{+}$(CD34-LSK, i.e., phenotypic HSCs) $(n=4-6) .{ }^{* *} P<0.01$ compared with Lin+ cells, and \#P<0.05 compared with Lin- cells. (B-D) Mice were sacrificed at ZT5 (5 hours after initiation of light) and ZT13 (1 hour after initiation of darkness). (B) GSK3 $\beta$ expression (fold change) was determined by flow cytometry in total BM cells, LK cells, LSK cells, and CD34-LSK cells at ZT5 and ZT13 $(n=3-5)$. PB was obtained to measure circulating WBCs (C) and LSK cells, indicating HSPCs (D) $(n=6)$. (E-H) Mice were treated with $10 \mathrm{mg} / \mathrm{kg}$ NE or PBS and sacrificed after 1 hour. PB was then obtained to measure circulating WBCs $(\mathbf{E})$ and LSK cells $(\mathbf{F})(n=5-8)$. (G) GSK3 $\beta$ expression was determined by flow cytometry in total BM cells, LK cells, LSK cells, and CD34-LSK cells 20 minutes after administration of NE $(n=4-6)$. (H) BM MNCs were obtained from PBS- or NE-treated mice and loaded into transwells. Migration toward $125 \mathrm{ng} / \mathrm{ml} \mathrm{CXCL12}$ was assessed for 2 hours. In addition, LK cells were measured among migrating BM MNCs $(n=3-5) .{ }^{*} P<0.05$ and ${ }^{* *} P<0.01$ compared with control (or between ZT5 and ZT13 time points). Ctrl, control.

HSPCs following IGF-1 administration (Figure 4, A-C). These observations suggest that IGF-1 enhances HSPC retention in the BM, limiting their egress to the PB. Notably, GSK3 $\beta$ expression was downregulated preferentially in BM HSPCs, includ- ing phenotypic HSCs, in response to IGF-1 administration, implying involvement of GSK3 $\beta$ (Figure 4D), without apparent changes in inactive pS9-GSK3 $\beta$ levels (Supplemental Figure 2D). Reduced steady-state egress does not necessarily indicate 

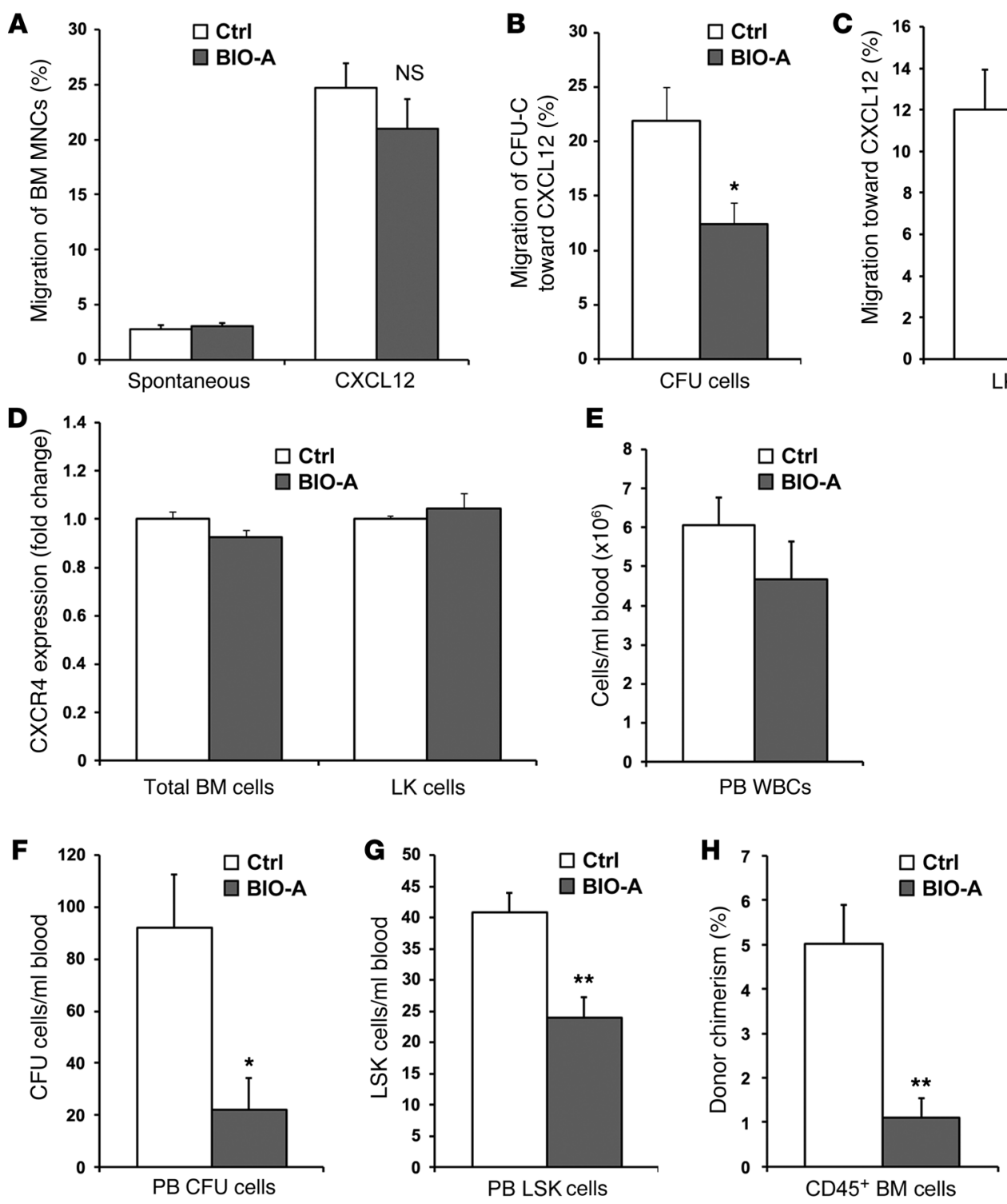

Figure 2

GSK3 $\beta$ is preferentially involved in HSPC motility. (A) BM MNCs were pretreated with $1 \mu \mathrm{M}$ BIO-A (a selective GSK3 $\beta$ inhibitor) or equivalent DMSO for 1 hour and then loaded into Transwells. Migration was assessed for 2 hours as being either spontaneous or toward $125 \mathrm{ng} / \mathrm{ml} \mathrm{CXCL} 12$ $(n=8)$. (B) CXCL12-induced migrating BM MNCs were washed and then seeded into methylcellulose colony assay to measure CFU cells, indicating HSPCs. (C) In addition, LK cells were measured among migrating BM MNCs $(n=3-5)(\mathbf{C})$, and CD34-LSK cells were measured among migrating Lin- cells $(n=5-6)$. (D) Following treatment with $1 \mu \mathrm{M}$ BIO-A or equivalent DMSO for 1 hour, CXCR4 expression (fold change) was determined by flow cytometry in total BM and LK cells $(n=3)$. (E-G) Mice were treated with $0.6 \mathrm{mg} / \mathrm{kg} \mathrm{BIO-A}$ or equivalent DMSO. After 1 hour, they were sacrificed and PB was obtained to measure circulating WBCs $(\mathbf{E})$, as well as circulating CFU cells $(\mathbf{F})$ and LSK cells $(\mathbf{G})(n=4)$. $(\mathbf{H})$ LTR assay by PB HSCs. Donor mice were treated with $0.6 \mathrm{mg} / \mathrm{kg} \mathrm{BIO-A} \mathrm{or} \mathrm{equivalent} \mathrm{DMSO,} \mathrm{and} \mathrm{after} 1$ hour the PB was collected. Congenic recipient mice were lethally irradiated (10 Gy) 24 hours prior to transplantation. Each recipient mouse was transplanted with $500 \mu l$ of donor PB along with $200 \times 10^{3}$ host-type competitive BM cells. Donor chimerism in the recipient BM was evaluated 4 months after transplantation $(n=5-6)$. ${ }^{\star} P<0.05$ and ${ }^{* *} P<0.01$ in comparison with control. NS, nonsignificant.

reduced motility and might result from other non-cell-autonomous effects restricting the egress of cells to the circulation. In order to overcome this bias, BM MNCs were derived from IGF-1- or PBS-treated mice to evaluate their CXCL12-induced migration in vitro. Notably, BM MNCs and, more strongly, HSPCs and phenotypic HSCs that were derived from IGF-1treated mice, demonstrated reduced migratory capacity toward
CXCL12 compared with cells from control mice (Figure 4E), supporting our hypothesis regarding the direct effects of GSK3 $\beta$ on cell motility. Surface CXCR4 levels were unaltered on BM MNCs and HSPCs, suggesting an independence of reduced chemotaxis to CXCL12 on CXCR4 membrane expression (Figure $4 \mathrm{~F}$ ). It should be noted that IGF-1 may indirectly regulate GSK3 $\beta$ in BM HSPCs, as in vitro treatment has no effect (data 


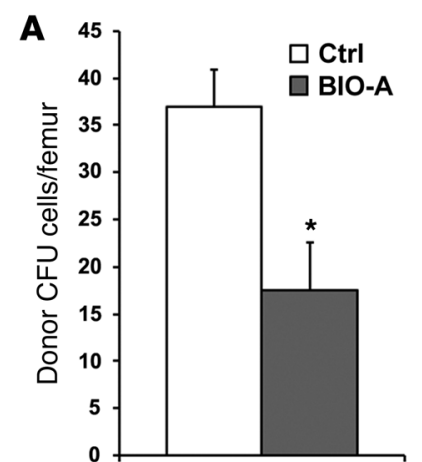

BM CFU cells
B

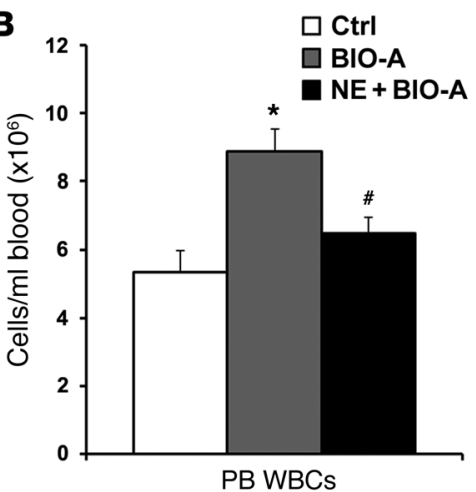

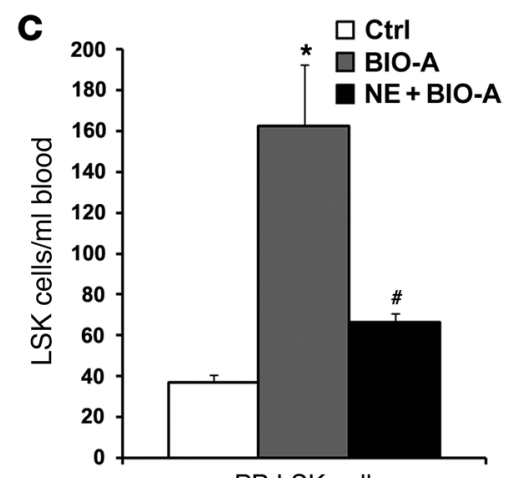

PB LSK cells

Figure 3

GSK3 $\beta$ is preferentially involved in HSPC motility (continued). (A) NOD/SCID mice were lethally irradiated (6 Gy) to deplete host BM CFU cells. Donor BM MNCs were pretreated with $1 \mu \mathrm{M}$ BIO-A or equivalent DMSO for 1 hour and then transplanted 24 hours after irradiation ( $5 \times 10^{6}$ cells per mouse). After 16 hours of homing, BM was obtained and donor CFU cells were evaluated $(n=3-5)$. (B and C) Mice were injected twice with $0.6 \mathrm{mg} / \mathrm{kg}$ BIO-A or equivalent DMSO, 60 and 30 minutes before administration of $10 \mathrm{mg} / \mathrm{kg} \mathrm{NE}$. One hour after NE administration, mice were sacrificed and PB was obtained to measure circulating WBCs (B) and LSK cells $(\mathbf{C})(n=4)$. ${ }^{*} P<0.05$ compared with control; ${ }^{P} P<0.05$ compared with NE treatment.

not shown). Altogether, we suggest that IGF-1 treatment led to the downregulation of GSK3 $\beta$ expression, which in turn reduced HSPC motility and consequently increased HSPC retention in the $\mathrm{BM}$ at the expense of their egress into the circulation. In order to further evaluate the crosstalk between IGF-1R signaling and GSK3 $\beta$, an IGF-1R antagonist (PQ401) was given to mice and the steady-state egress of WBCs and HSPCs was assessed after 1 hour. PQ401 was able to enhance WBC and HSPC egress (Figure 5, A-C, and Supplemental Figure 3C), as opposed to the effect of prolonged IGF-1 treatment, which reduced the steady-state egress of WBCs and HSPCs (Figure 4, A-C). To verify the involvement of GSK3 $\beta$ in this rapid mobilization, the GSK3 $\beta$ inhibitor BIO-A was coadministered with PQ401. Indeed, BIO-A abolished PQ401-induced mobilization of WBCs and HSPCs, supporting the observation that GSK3 $\beta$ acts downstream of IGF-1R (Figure 5, A-C). Of note, BM HSPC levels were also examined and found to be unaffected by PQ401 treatment (Supplemental Figure 4, A and B). In a similar fashion to the reduced migratory capacity of BM HSPCs from IGF-1-treated mice (Figure 4E), HSPCs from the BM of PQ401-treated mice demonstrated increased migration toward CXCL12 (Figure 5D). Moreover, the homing capacity of progenitor cells was found to be increased following PQ401 treatment (Figure 5E), further supporting increased HSPC motility following IGF-1R signaling inhibition. Both migratory and homing capacities were partially counteracted by BIO-A cotreatment in vivo (Figure 5, D and E). In conclusion, our results show that upregulation or downregulation of GSK3 $\beta$ expression in HSPCs led to augmented or suppressed directional motility, which is also translated into enhanced or restricted in vivo egress rates, respectively.

SCF preferentially enhances HSPC motility by activating GSK3 $\beta$ in HSPCs. We wondered how GSK $3 \beta$ signaling preferentially promotes HSPC motility over mature leukocytes, apart from the observation that they express higher GSK3 $\beta$ levels. Since cKit is a common marker for HSPCs (32), and its ligand SCF is involved in both human and murine HSPC motility (28-30), we investigated a possible crosstalk with GSK3 $\beta$. Pretreatment with SCF had no effect on the spontaneous or CXCL12-induced migration of BM MNCs, as expected, since the vast majority of BM MNCs do not express cKit (Figure 6A). On the contrary, the migratory potential of cKit-expressing HSPCs, including phenotypic HSCs, toward CXCL12 was increased following pretreatment with SCF (Figure 6B). Importantly, cotreatment with GSK3 $\beta$ inhibitor could block this enhanced migratory effect only in HSPCs, reducing directional migratory potential back to normal levels (Figure $6 \mathrm{~B})$. Furthermore, GSK3 $\beta$ expression was specifically increased in HSPCs, including phenotypic HSCs (Figure 6C), together with upregulation of pS9-GSK3 $\beta$ and pY216-GSK3 $\beta$ levels (Supplemental Figure 2E), indicating increased activity of GSK3 $\beta$. There was a positive correlation between the effect of SCF on GSK3 $\beta$ expression and its effect on migratory potential, as phenotypic HSCs showed a higher increase in GSK3 $\beta$ expression and migratory potential compared with less primitive HSPCs. Of note, CXCR4 levels were unaltered in HSPCs following short-term treatment with SCF (Figure 6D). Interestingly, we observed downregulation of SCF in BM sections of IGF-1-treated mice compared with PBS-treated mice (Figure 6E, see also Figure 4, A-C), suggesting a possible IGF-1-mediated mechanism that results in GSK3 $\beta$ downregulation and consequently lower HSPC motility (Figure 4, D and E). Taken together, these results suggest that SCF/cKit signaling uniquely promotes directional migratory potential of HSPCs in a GSK3 $\beta$-dependent manner.

GSK3 $\beta$ signaling regulates actin and MT rearrangement in HSPCs. The findings so far suggest that GSK3 $\beta$ signaling promotes directional HSPC migration in response to chemotactic stimuli, such as CXCL12. Thus, it is logical to assume that the downstream mechanisms involve nongenomic effects, such as regulation of cell cytoskeletal dynamics. HSPCs quickly polymerize actin filaments in response to CXCL12 (36), allowing chemotaxis. We therefore examined whether inhibition of this pathway could abolish this rapid response. Indeed, inhibition of GSK3 $\beta$ by BIO-A prior to stimulation by CXCL12 reduced the capacity of $\mathrm{CKit}^{+} \mathrm{HSPCs}$ and phenotypic HSCs to polymerize actin (Figure 7, B and C). Of note, GSK3 $\beta$ inhibition had a minor and nonsignificant effect on CXCL12-induced actin polymerization in BM MNCs compared with HSPCs (Figure 7A), strengthening the concept of a preferential role for a 


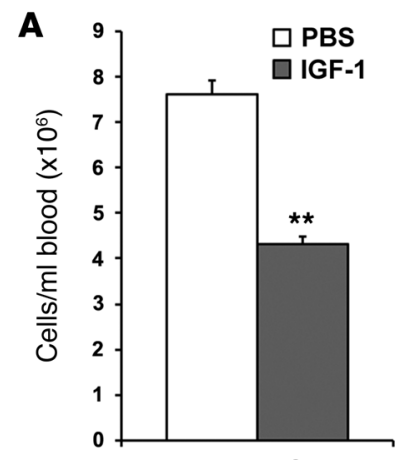

PB WBCs

D

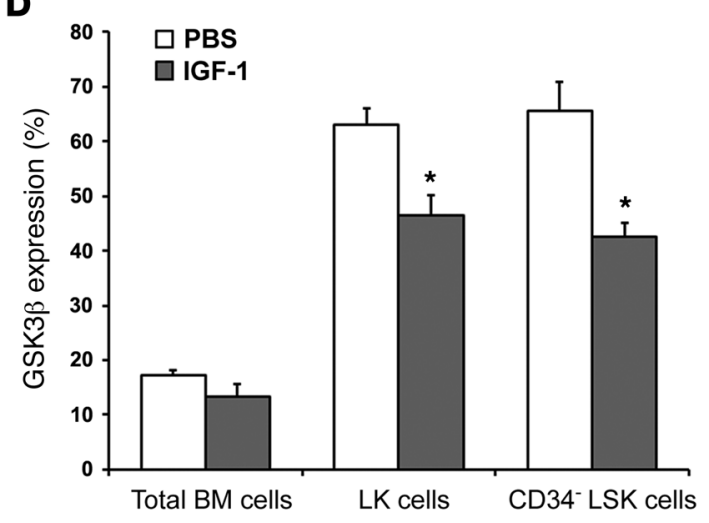

F

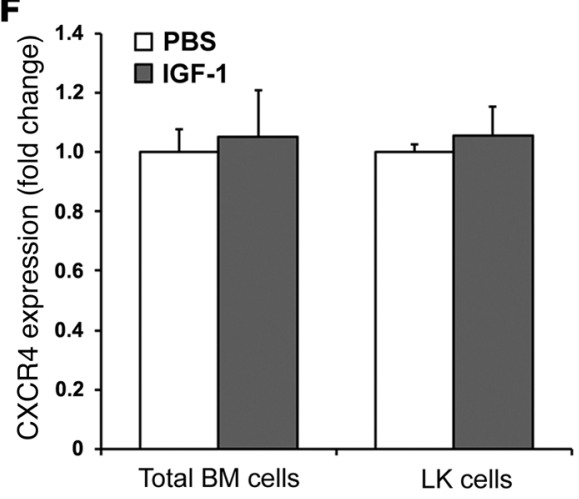

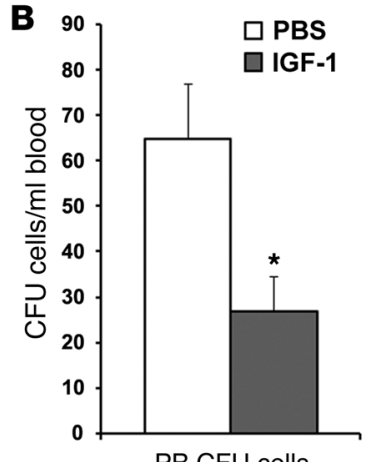

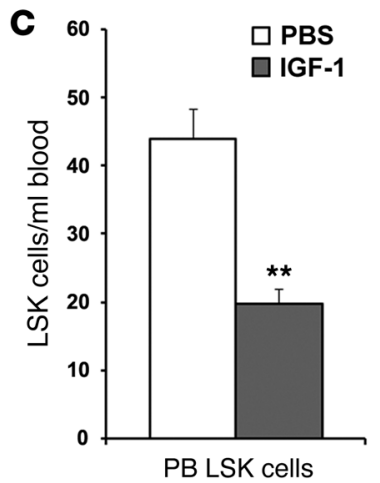

\section{E}

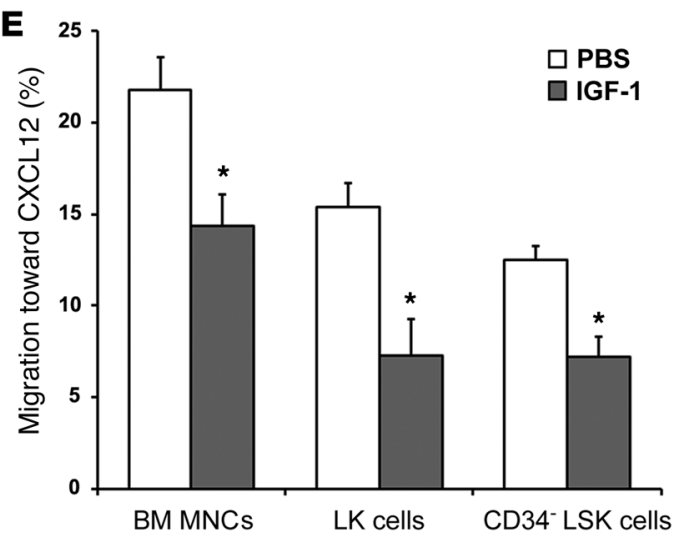

\section{Figure 4}

IGF-1 regulates HSPC motility in a GSK3 $\beta$-dependent manner. Mice were i.p. injected with PBS or $5 \mu$ IGF-1 per mouse per day for 7 consecutive days and sacrificed 4 hours after the last injection to measure circulating WBCs (A), as well as circulating CFU cells (B) and LSK cells (C) ( $n=6-9)$. (D) GSK3 $\beta$ expression (percentage of positive cells) was determined by flow cytometry in total BM cells, LK cells, and CD34- LSK cells $(n=4-8)$. (E) BM MNCs were obtained from PBS or IGF-1 treated mice and loaded into Transwells. Migration toward $125 \mathrm{ng} / \mathrm{ml}$ CXCL12 was assessed for 2 hours. In addition, LK cells were measured among migrating BM MNCs $(n=4-6)$, and CD34-LSK cells were measured among migrating Lin- cells $(n=5-7)$. (F) CXCR4 expression (fold change) was determined by flow cytometry in total BM cells and LK cells $(n=4)$.

GSK3 $\beta$ signaling pathway in immature cells. Moreover, we tested actin polarization and formation of protrusions in response to CXCL12 following inhibition of GSK3 $\beta$. HSPCs were isolated from murine BM and were pretreated with GSK3 $\beta$ inhibitor prior to stimulation with CXCL12. We examined the $\mathrm{CKit}^{+}$cell population and the phenotypic HSCs and found that fewer cells exhibited polarized actin and formation of protrusions (Figure 7, D-F) compared with CXCL12-only stimulated cells, supporting the observation that reduced CXCL12-induced actin polymerization occurs upon GSK3 $\beta$ inhibition. Examples of polarized versus nonpolarized CD34- LSK
HSCs and $\mathrm{CD}_{34}{ }^{+}$LSK HSPCs are presented in Figure 7F and Supplemental Figure 5. Since turnover of the MT network is also essential for cell migration, we hypothesized that GSK3 $\beta$ promotes MT turnover as well. Acetylation of MT filaments is associated with their stability (45), thus we evaluated the content of acetylated tubulin in BM HSPCs and phenotypic HSCs upon GSK3 $\beta$ inhibition. Surprisingly, an increased amount of acetylated tubulin was found in HSPCs, and an even larger amount in phenotypic HSCs (Figure 8A), suggesting that the MT filaments were overstabilized in GSK3 $\beta$-inhibited HSPCs. Nocodazole is applied as a depolymerization agent 
A

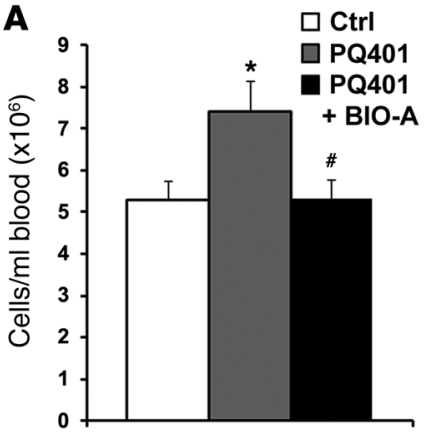

PB WBCs

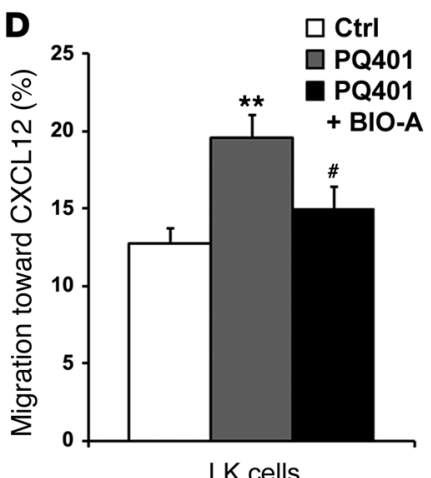

B

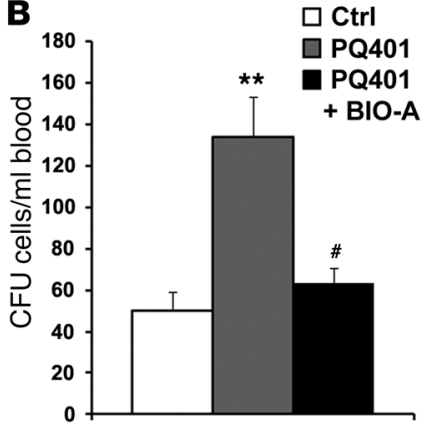

PB CFU cells

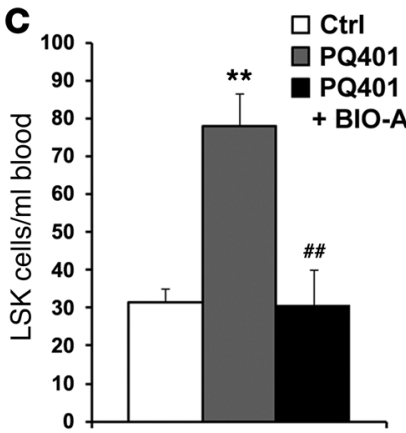

PB LSK cells

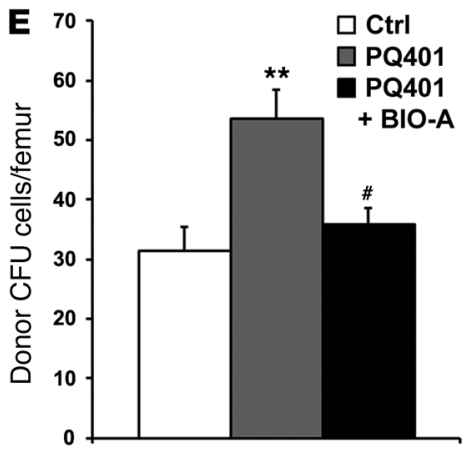

BM CFU cells

Figure 5

IGF-1R antagonist promotes hematopoietic progenitor cell motility in a GSK3 $\beta$-dependent manner. Mice were treated with $10 \mathrm{mg} / \mathrm{kg}$ PQ401 (IGF-1R antagonist) with or without $0.6 \mathrm{mg} / \mathrm{kg} \mathrm{BIO-A} \mathrm{or} \mathrm{equivalent} \mathrm{DMSO.} \mathrm{After} 1$ hour, they were sacrificed and their PB was obtained to measure circulating WBCs (A), as well as circulating CFU cells (B) and LSK cells (C) $(n=4-6)$. (D) BM MNCs were obtained from DMSO/PQ401/ PQ401 plus BIO-A-treated mice and loaded into Transwells. Migration toward $125 \mathrm{ng} / \mathrm{ml}$ CXCL12 was assessed for 2 hours. In addition, LK cells were measured among migrating BM MNCs $(n=6-8)$. (E) NOD/SCID mice were lethally irradiated (6 Gy) to deplete host BM CFU cells. Donor BM MNCs were obtained from DMSO/PQ401/PQ401 plus BIO-A-treated mice and then transplanted 24 hours after irradiation $\left(5 \times 10^{6}\right.$ cells per mouse). After 16 hours of homing, BM was obtained and donor CFU cells were evaluated $(n=5-7) .{ }^{*} P<0.05$ and ${ }^{* *} P<0.01$ compared with control; ${ }^{\#} P<0.05$ and ${ }^{\#} P<0.01$ compared with $\mathrm{PQ} 401$ treatment.

for MT and is able to restore cell migration, in which there is no MT turnover (39). According to our hypothesis, the GSK3 $\beta$ inhibitor attenuates MT turnover, resulting in reduced motility and partial depolymerization of overstabilized MT filaments that would refacilitate MT turnover, while full depolymerization of MT filaments would not. We therefore added nocodazole to BM MNCs prior to subjecting them to a Transwell migration assay. Indeed, the addition of nocodazole at a low concentration to GSK3 $\beta$-inhibited HSPCs and phenotypic HSCs restored their CXCL12-induced migratory capacity, whereas the addition of nocodazole at a high concentration did not (Figure 8, B and C). Nocodazole at these concentrations had nonsignificant subtle effects over BM MNC migration (data not shown), once again showing preferential effects on immature hematopoietic cells. These data suggest that GSK3 $\beta$ signaling promotes directional HSPC migration by controlling the rearrangement of the actin and MT cytoskeleton.

\section{Discussion}

Homeostatic egress of HSPCs from the BM to the blood circulation is necessary for surveillance as part of host defense and repair mechanisms $(1,46)$. HSPCs constitutively egress and home back to their BM niches. Furthermore, circulating HSPCs display cir- cadian oscillations, which are driven by adrenergic signals from the sympathetic nervous system (22). This egress is substantially enhanced during stress conditions or upon clinical administration of mobilizing agents (2). Accumulating evidence contradicts the concept of passive release for steady-state egress of HSPCs and instead supports the notion of highly regulated active and durable egress. For example, inhibition of sphingosine-1-phosphate receptor 1 (S1P1) (47) or CXCL12/CXCR4 neutralization by antibodies (24) results in reduced steady-state egress of HSPCs, suggesting that active signaling is required for homeostatic egress from the $\mathrm{BM}$ to the circulation. Additionally, the mere concept of a circadian molecular clock controlling HSPC egress supports the notion of highly regulated homeostasis of HSPC trafficking (48). Several reports have described a function for GSK3 $\beta$ in cell motility (13-16), but it has not been determined whether it plays any role in immature hematopoietic cell motility.

GSK3 $\beta$ signaling promotes HSPC motility. Apart from its role in HSC self-renewal (3-6), we revealed an unexpected role of GSK3 $\beta$ in preferentially regulating directional motility mechanisms of murine HSPCs over mature leukocytes, as demonstrated in the current study by in vitro migration of these HSPCs toward CXCL12 and their steady-state egress, rapid mobilization, and 
A

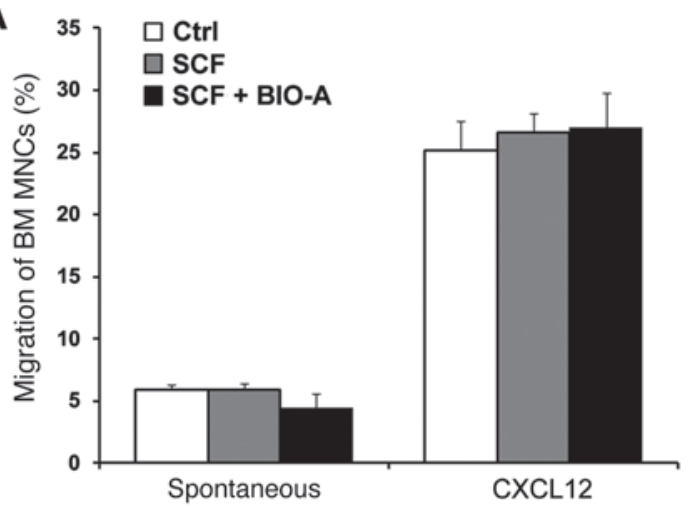

B

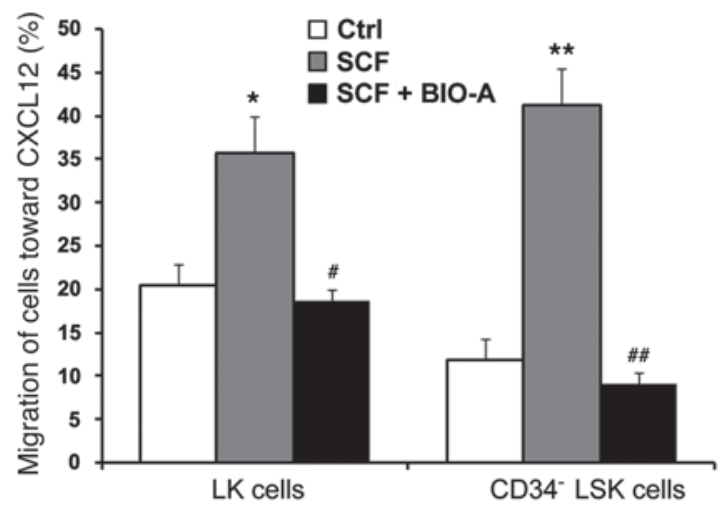

C

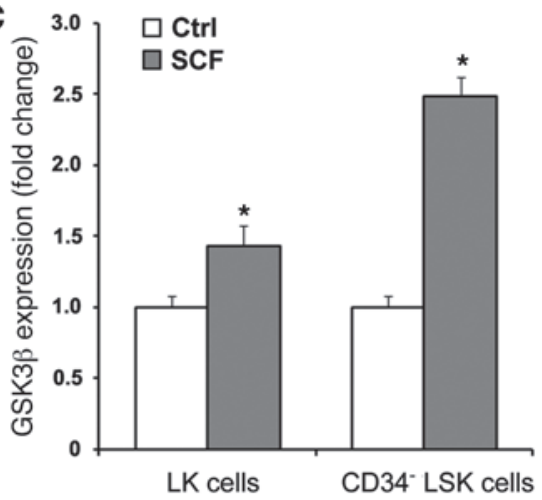

D

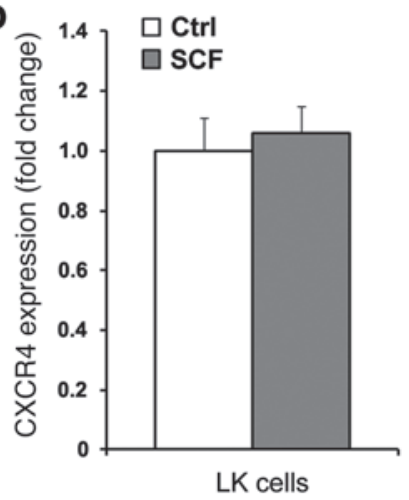

E

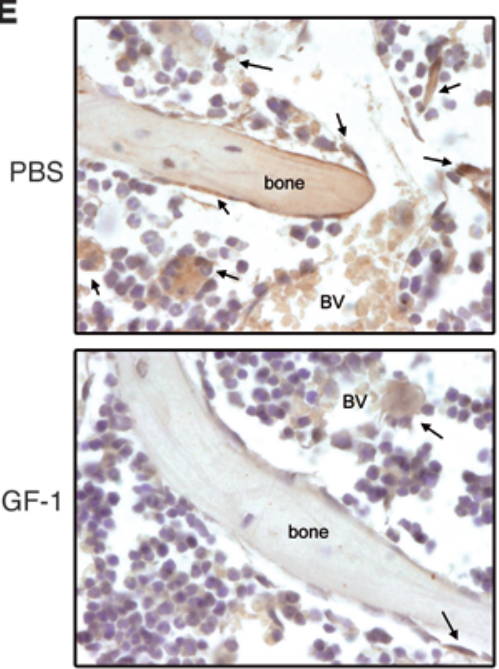

\section{Figure 6}

SCF selectively enhances HSPC motility by activating GSK3 $\beta$ in HSPCs. (A-D) Indicated cells were pretreated or not with $100 \mathrm{ng} / \mathrm{ml}$ SCF together with $1 \mu \mathrm{M}$ BIO-A or equivalent DMSO for 4 hours. (A) BM MNCs were loaded into Transwells. Migration was assessed for 2 hours as being either spontaneous or toward $125 \mathrm{ng} / \mathrm{ml} \mathrm{CXCL12}(n=5-6)$. (B) In addition, LK cells were measured among migrating BM MNCs $(n=3-4)$, and CD34- LSK cells were measured among migrating Lin- BM cells $(n=8)$. (C) GSK3 $\beta$ expression (fold change) was determined by flow cytometry in LK cells $(n=5-6)$, and in CD34- LSK cells $(n=4-5)$. (D) CXCR4 expression (fold change) was determined by flow cytometry in LK cells $(n=6)$. (E) Immunohistochemistry for SCF (brown) in the BM after administration of PBS or IGF-1 for 7 consecutive days. Representative images are shown from 3 independent experiments. Original magnification, $x 600$. Arrows point to SCF-expressing cells. BV, blood vessel or sinusoid. ${ }^{*} P<0.05$ compared with control; ${ }^{\#} P<0.05$ compared with SCF treatment; ${ }^{* *} P<0.01$ compared with control; and $\# \#<0.01$ compared with SCF treatment.

homing (summarized in Figure 9). It was also demonstrated that the physiological egress of functional LTR HSCs is controlled by GSK3 $\beta$ activity. However, since we did not perform an analysis of multilineage donor cell repopulation, we cannot exclude the possibility that GSK3 $\beta$ inhibition caused skewing of the donor HSC repopulating capacity. Our findings suggest that GSK $3 \beta$ signaling in a synchronized fashion with the CXCL12/CXCR4 axis allows directional migration of HSPCs, which is also manifested in their physiological egress. CXCL12 stimulation by itself did not activate GSK3 $\beta$, and GSK3 $\beta$ inhibition did not alter CXCR4 expression. GSK3 $\beta$ activity, therefore, increases the sensitivity of immature cells to chemotactic cues (i.e., CXCL12) without affecting or being directly affected by CXCL12/CXCR4 signaling. The crosstalk between GSK3 $\beta$ and CXCR 4 pathways therefore requires further clarification, hinting at a possible convergence through unknown downstream mediators.
SCF enhances HSPC migration via GSK3 $\beta$. Notably, higher GSK3 $\beta$ expression was seen in immature hematopoietic cells, including progenitor cells and phenotypic HSCs, an observation that was also recently supported by others (49), and suggests that HSPCs would be more sensitive to GSK3 $\beta$ inhibition. The preferential effect of GSK3 $\beta$ inhibition on immature versus mature hematopoietic cells is intriguing and led us to search for a unique GSK3 $\beta$ mediated signaling pathway involved in the motility of immature hematopoietic cells. In line with reports on enhanced migration and homing potential following exposure to SCF (28-30) and the reduced migratory potential of cKit-deficient immature hematopoietic cells (27), we studied cKit signaling as a potential upstream regulator of GSK3 $\beta$ activity. Indeed, we observed that exposure to SCF enhanced the in vitro migration of HSPCs, especially the more primitive phenotypic HSCs, toward CXCL12 in a GSK3 $\beta$-dependent manner. Prolonged in vitro treatment (2-5 
A

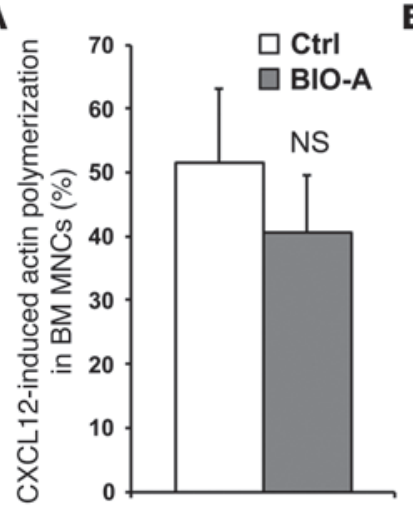

B

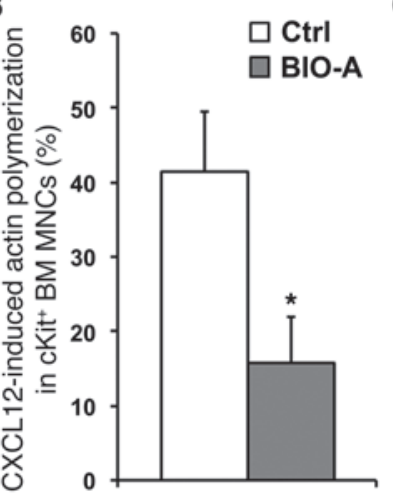

C
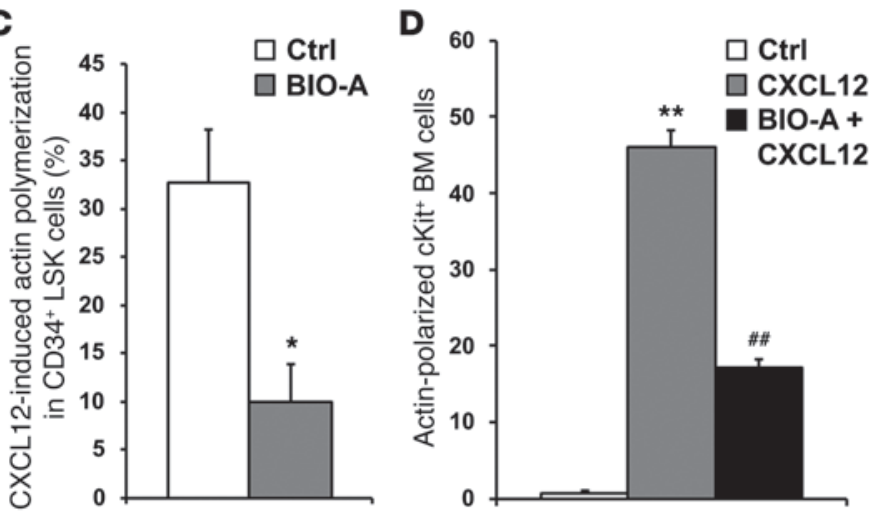

E

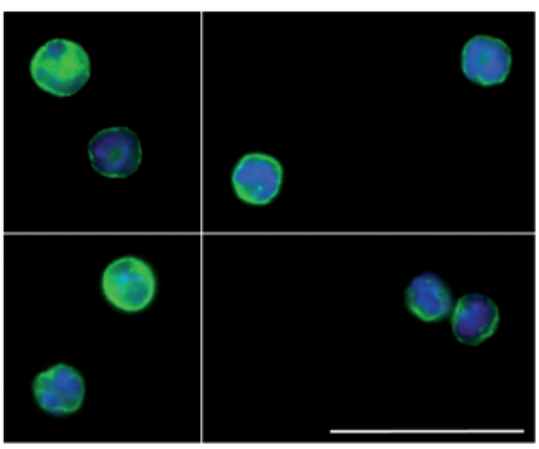

DMSO

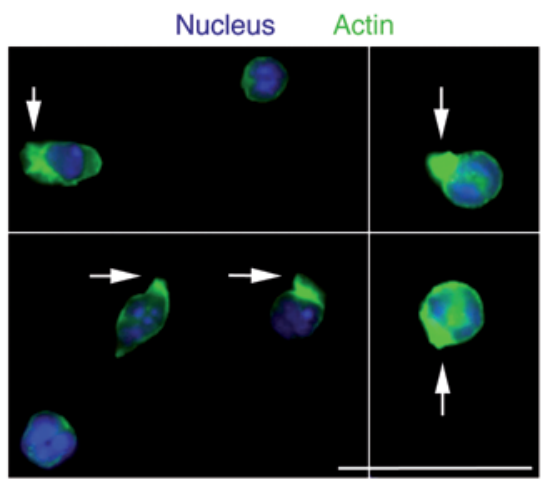

DMSO + CXCL12

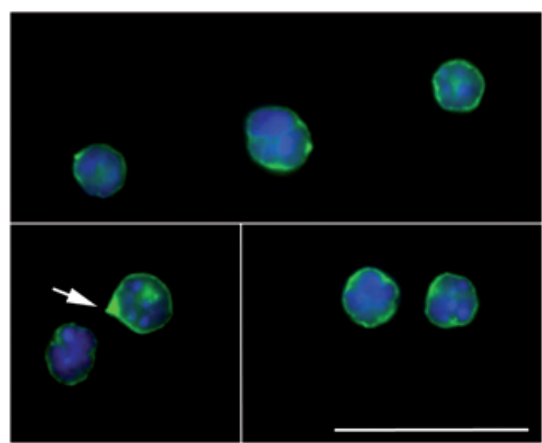

BIO-A + CXCL12

F Of Lin- cells:

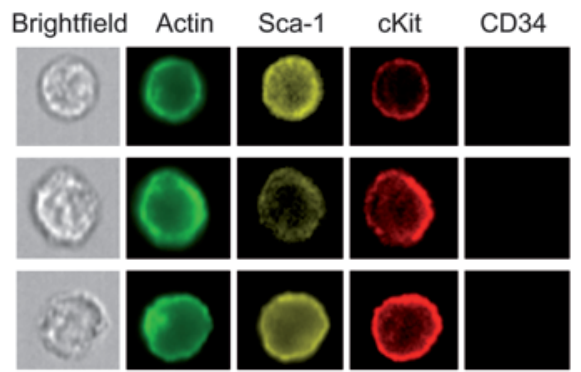

DMSO

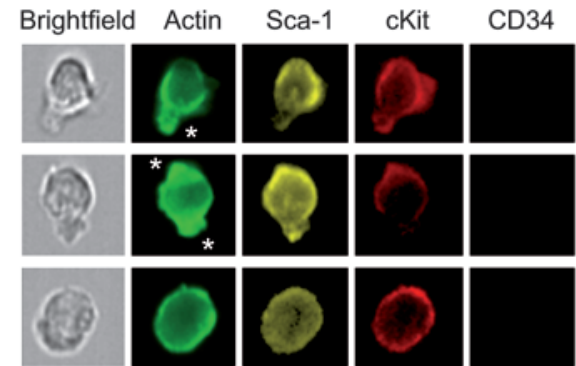

DMSO + CXCL12

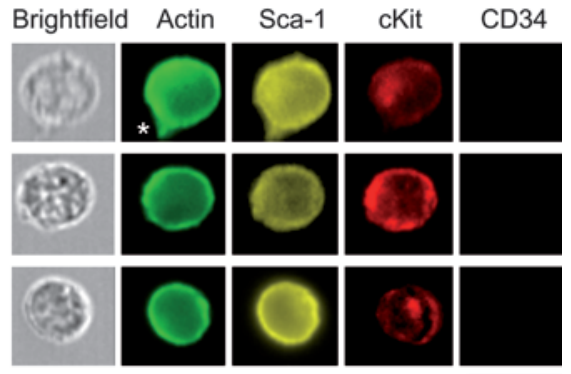

BIO-A + CXCL12

Figure 7

GSK3 $\beta$ signaling regulates actin rearrangement in HSPCs. (A-C) BM MNCs or Lin- BM cells were pretreated with $1 \mu$ M BIO-A or equivalent DMSO for 1 hour and then stimulated with $200 \mathrm{ng} / \mathrm{ml} \mathrm{CXCL12} \mathrm{for} 30$ seconds. CXCL12-induced actin polymerization rates were assessed by measuring F-actin content in fixed/permeabilized cells using phalloidin-FITC and flow cytometry. The percentage difference in actin content between nonstimulated cells and stimulated cells equals the actin polymerization rate. CXCL12-induced actin polymerization in BM MNCs (A), cKit ${ }^{+}$cells (B), and CD34- LSK cells (C) $(n=5)$. (D-F) Isolated cKit+ BM cells ( $\mathbf{D}$ and $\mathbf{E})$ or Lin- cells $(\mathbf{F})$ were pretreated with $1 \mu \mathrm{M}$ BIO-A or equivalent DMSO for 1 hour and then stimulated or not with $200 \mathrm{ng} / \mathrm{ml} \mathrm{CXCL12} \mathrm{for} 5$ minutes. Actin polarization was assessed in fixed/permeabilized cells using phalloidin-FITC. (D) Quantification of polarized cKit ${ }^{+} \mathrm{BM}$ cells by assessing 20 random fields per sample in 2 independent experiments. (E) Representative images of cKit ${ }^{+}$cells are shown. Actin is shown in green; arrows point to cell protrusions in response to CXCL12 stimuli. Hoechst indicates cell nuclei (blue). Scale bars: 20 um. (F) Representative flow cytometry-based single-cell images of CD34- LSK cells as obtained by ImageStream. DMSO: 3 of 3 nonpolarized cells; CXCL12: 2 of 3 polarized cells; BIO-A plus CXCL12: 1 of 3 polarized cells. Asterisks point to cell protrusions in response to CXCL12 stimuli. Original magnification, $\times 600$. ${ }^{*} P<0.05$ compared with control; ${ }^{* \star} P<0.01$ compared with control; and ${ }^{\# \#} P<0.01$ compared with $C X C L 12$ stimulation.

days) with SCF also augments the CXCL12-induced migratory potential of murine and human HSPCs $(50,51)$. Furthermore, prolonged SCF treatment of human CD34 ${ }^{+}$HSPCs increases CXCR4 surface expression, resulting in their enhanced homing potential toward the BM of recipient NOD/SCID mice (51). Additionally, W/Wv mice, having defective cKit kinase activity, do not mobilize in response to AMD3100 administration and demonstrate low expression of surface CXCR4 on HSPCs (26). Nevertheless, the major difference between these GSK3 $\beta$ pathway findings (days or constant deficiency) and our findings (hours) is noted in the CXCR4 expression-dependent effects versus the CXCR4 expression-independent effects, respectively. 


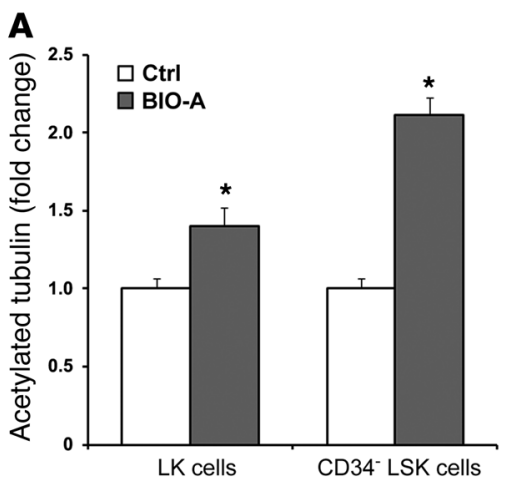

B

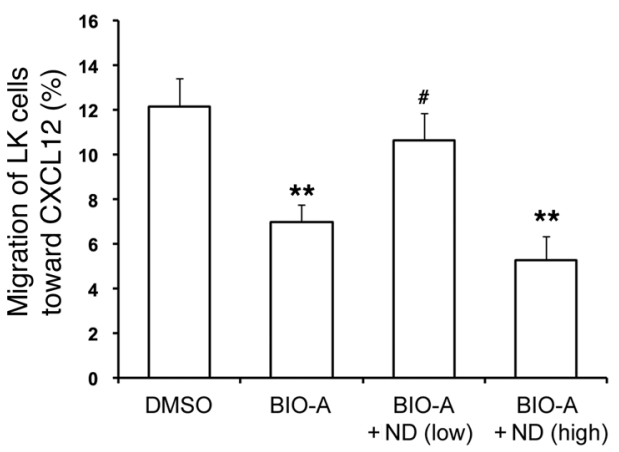

C

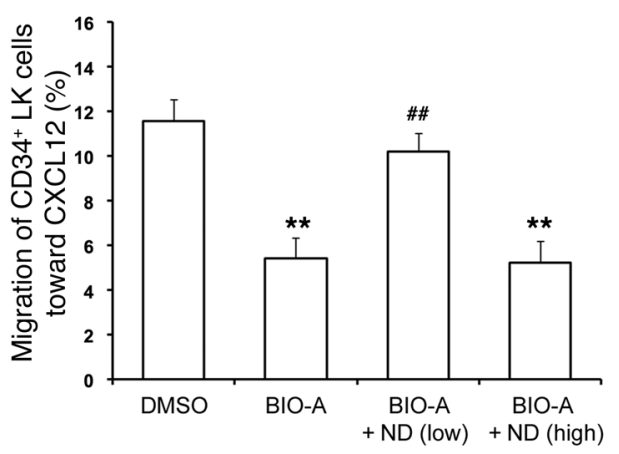

Figure 8

GSK3 $\beta$ signaling regulates MT turnover in HSPCs. (A) Total BM cells were pretreated with $1 \mu \mathrm{M}$ BIO-A or equivalent DMSO for 1 hour and the content of acetylated tubulin (fold change) was determined by flow cytometry in LK cells $(n=7)$, and in CD34- LSK cells $(n=5)$. (B and C) BM MNCs or Lin- BM cells were pretreated with $1 \mu \mathrm{M}$ BIO-A or equivalent DMSO for 1 hour, after which they were treated with nocodazole (ND, low concentration of $0.5-1 \mu \mathrm{M}$, or high concentration of $10 \mu \mathrm{M}$ ) or equivalent DMSO for 15 minutes and then loaded into Transwells. Migration of LK cells (B) or CD34- LSK cells (C) toward $125 \mathrm{ng} / \mathrm{ml} \mathrm{CXCL12} \mathrm{was} \mathrm{assessed} \mathrm{for} 2$ hours $(n=5-6) .{ }^{*} P<0.05$ and ${ }^{* *} P<0.01$ compared with control; $\# P<0.05$ compared with BIO-A treatment; and ${ }^{\#} P<0.01$ compared with CXCL12 treatment. NS, nonsignificant.

Adrenergic signals control physiological egress of HSPCs via GSK3ß. While it is believed that circadian NE levels regulate HSPC egress rates via regulation of CXCL12 synthesis in the BM and CXCR4 expression $(22,40)$, our results point to additional CXCL12/ CXCR4-independent regulation of homeostatic HSPC trafficking. We demonstrate that GSK3 $\beta$ expression levels in BM HSPCs correlate with their circadian egress rates, and stimulation with the sympathetic nervous system neurotransmitter NE induces rapid HSPC mobilization in a GSK3 $\beta$-dependent manner. Interestingly, the elevation in GSK3 $\beta$ expression after NE stimulation was detected only in HSPCs, and the more primitive the HSPCs, the higher the GSK3 $\beta$ elevation. This observation implies a yet unknown mobilization mechanism that is selective for HSPCs. Mature leukocytes may use other mechanisms for their mobilization, such as protease activation (24) and chemokine release in addition to CXCL12. Hence, we suggest that circadian adrenergic signals guide HSPC trafficking via GSK3 $\beta$-mediated cell-autonomous motility mechanisms in addition to non-cell-autonomous mechanisms (e.g., CXCL12 levels). It has yet to be determined how GSK3 $\beta$ activity is regulated by circadian rhythms and how it affects HSPC egress.

IGF-1 signaling controls HSPC motility via GSK3$\beta$. We were able to manipulate GSK3 $\beta$ activity in HSPCs by treating mice with agonists or antagonists, consequently affecting HSPC egress. For example, the administration of IGF-1 for 7 consecutive days, which downregulated GSK3 $\beta$ expression in BM HSPCs, led to reduced egress due to a diminished migratory potential toward CXCL12, regardless of CXCR4 expression. Intriguingly, we observed the downregulation of SCF expression in the BM following IGF-1 administration, which might suggest that a lack of SCF lowers HSPC motility in these mice. On the contrary, administration of the IGF-1R antagonist, which rapidly altered this homeostatic signaling cascade, resulted in GSK3 $\beta$-dependent HSPC mobilization due to their increased motility. Higher migratory and homing capacities were observed following administration of the IGF-1R antagonist in a GSK3 $\beta$-dependent manner, further supporting the role for GSK3 $\beta$ upstream
IGF-1R signaling in HSPC motility. Since IGF-1 promotes HSPC expansion (34) and IGF-R blockage may affect HSPC developmental potential (52), IGF-1 signaling has an impact on stem cell development, apart from its effects on HSPC motility. Thus, repopulation assays could not be conducted to determine circulating LTR HSC levels following in vivo treatment with IGF-1 or the IGF-1R antagonist.

GSK3 $\beta$ regulates $H S P C$ motility via cytoskeletal rearrangement. We observed that CXCL12-induced actin polymerization and polarization, which are integral to cell movement, including movement of HSPCs $(36,53)$, are perturbed upon inhibition of GSK3 $\beta$. Not only were actin dynamics found to be controlled by GSK $3 \beta$, but MT turnover was as well. GSK3 $\beta$ inhibition attenuated MT turnover, and acceleration of MT turnover by using nocodazole at a low concentration was able to restore the migratory potential of GSK3 $\beta$-inhibited HSPCs. Involvement of MT turnover in response to CXCL12 has already been shown in human CD34+ HSPCs (39). Of interest, GSK3 $\beta$, together with CDC42 and APCs, exert cell polarity and MT reorganization in migrating rat astrocytes (54), suggesting that similar mechanisms may occur in murine HSPCs as well.

Conclusions and future directions. We assume that ongoing steadystate hematopoiesis requires strict retention of HSPCs in their BM niches, and that the loss of retention is thus associated with defects in hematopoiesis. There are few mechanisms, such as inducible genetic deletions of CXCR4 (19, 55), CXCL12 (20), RAC1, and CDC42 GTPases $(56,57)$, that result in increased numbers of HSPCs in the circulation and reduced repopulation potential. On the other hand, we demonstrate that FGF-2 or IGF-1 administration expanded HSPC numbers in the BM (data not shown and refs. 34,58 ), and consequently reduced their numbers in the PB. This is supported by the observation that both treatment with FGF-2 or IGF- 1 and direct GSK3 $\beta$ inhibition trigger HSPC proliferation in vitro $(6,59,60)$. Obviously, many signaling molecules are essential for HSPC motility and development, however, the functional linkage between HSC retention (i.e., restriction of motility) and self-renewal could be an important foundation for future studies. Pro- 


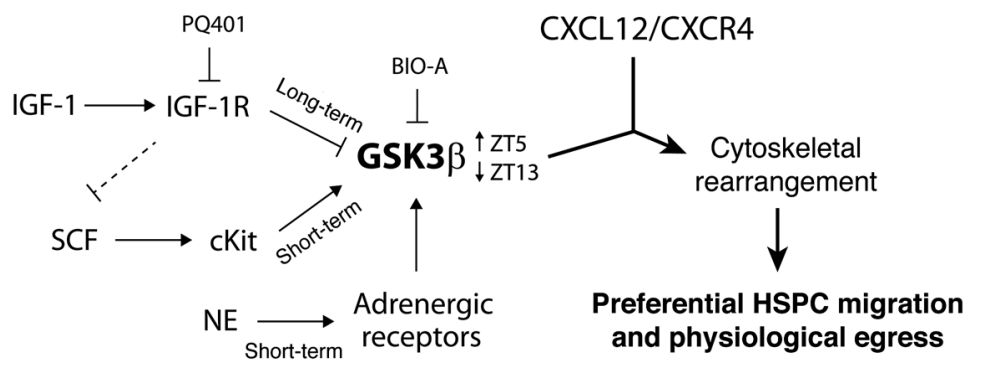

\section{Figure 9}

Flow chart shows how GSK3 $\beta$ signaling cooperates with CXCL12/CXCR4 signaling in murine HSPCs by governing their preferential and directional motility. At ZT5, GSK3 $\beta$ expression is at its peak as is the number of circulating HSPCs, whereas at ZT13, GSK3 $\beta$ expression is at its lowest point, as is the number of circulating HSPCs. GSK3 $\beta$ inhibition by BIO-A rapidly impairs HSPC steady-state egress and migratory potential. NE induces rapid mobilization of HSPCs and enhances their motility, demonstrating upregulated GSK3 $\beta$ expression. IGF- 1 administration for 1 week limits the egress of HSPCs and reduces their motility, demonstrating downregulated GSK3 $\beta$ expression. PQ401, which is an IGF-1R antagonist, induces rapid HSPC mobilization in a GSK3 $\beta$-dependent manner. In vitro SCF treatment enhances HSPC migratory capacity, demonstrating upregulated GSK3 $\beta$ expression. GSK3 $\beta$ signaling thereby promotes HSPC motility by controlling the rearrangement of cytoskeletal machinery (i.e., control over actin and MT dynamics). Short-term denotes hours; long-term denotes days.

moting directional migration by controlling the basic machinery of the cytoskeleton preferentially in immature cells is intriguing and suggests that physiological egress and recruitment of HSPCs from the BM to the PB is simply turned on by cell-autonomous mechanisms of movement. In our study, the functional links that connect GSK3 $\beta$ control over actin dynamics and MT turnover are still undefined and should be explored in future studies. Signaling that controls cytoskeletal rearrangement eventually terminates at machinery that directly regulates assembly or disassembly, stability, branching, and turnover of actin and MT filaments. In other words, inhibition of the GSK3 $\beta$ pathway renders a cell (i.e., HSPC) less motile due to interference with the dynamics of the cytoskeleton, thereby directly influencing its migratory potential toward chemotactic cues such as CXCL12. Deciphering the downstream and upstream mechanisms by which GSK3 $\beta$ signaling promotes directional motility of HSPCs will enable the understanding of how physiological egress and retention of HSPCs are regulated. These mechanisms may be used to improve clinical mobilization and transplantation protocols.

\section{Methods}

Cells. BM or PB MNCs were separated using Ficoll-Hypaque (Amersham Biosciences) density gradient centrifugation. All media for culturing cells were supplemented with $10 \%$ heat-inactivated FCS (Biological Industries), L-glutamine (Biological Industries), and penicillin and streptomycin antibiotics (Gibco; Invitrogen), and are thus described as full media unless otherwise indicated. Primary mouse cells were cultured in full RPMI 1640 (Biological Industries). Lineage-negative BM cells were enriched using a mouse lineage depletion kit (BD), according to the manufacturer's instructions. $\mathrm{KKit}^{+} \mathrm{BM}$ cells were positively isolated using anti-CD117 microbeads and midi-MACS LS columns (Miltenyi Biotec).

Mice. C57BL/6 and B6.SJL mice (8-12 weeks) were purchased from Harlan. The B6.SJL mice were self-maintained in the facility. Immune-deficient NOD/SCID mice were bred and maintained under defined flora conditions in individually ventilated (high-efficiency, particle-arresting filtered air) sterile microisolator cages (Techniplast) at the Weizmann Institute of Science (Rehovot, Israel) as described (51). Mice were sacrificed by $\mathrm{CO}_{2}$ inhalation. BM cells were obtained by flushing long bones with PBS, whereas PB was collected from the heart using heparinized syringes.
Reagents. The selective GSK3 $\beta$ inhibitor $\left(2^{\prime} Z, 3^{\prime} \mathrm{E}\right)$-6-bromoindirubin- $3^{\prime}$-acetoxime, BIO-A (Calbiochem) dose for in vitro treatment was $1 \mu \mathrm{M}$, and $0.6 \mathrm{mg} / \mathrm{kg}$ for in vivo treatment. The IGF-1R antagonist PQ401 (Sigma-Aldrich) dose for in vivo treatment was $10 \mathrm{mg} / \mathrm{kg}$. These reagents were dissolved in DMSO. Mouse SCF (Prospec-Tany TechnoGene) dose for in vitro treatment was $100 \mathrm{ng} / \mathrm{ml}$. The NE (Sigma-Aldrich) dose for in vivo treatment was $10 \mathrm{mg} / \mathrm{kg}$. In vitro treatments with these reagents were administered for 1 to 4 hours prior to the assay, whereas in vivo treatments were administered by i.p. injection and mice were sacrificed between 20 minutes to 2 hours afterward, depending on the experiment. Human IGF-1 (Reprokine) was given i.p. at a dose of $5 \mu \mathrm{g}$ per mouse for 7 consecutive days and mice were sacrificed approximately 4 hours after the last injection. Nocodazole (Sigma-Aldrich) was used as a microtubuli depolymerization agent.

Flow cytometry analyses. Phenotypes of murine cells were examined by immunostaining followed by flow cytometry analysis on FACSCalibur (BD) or on MacsQuant (Miltenyi Biotec) instruments. A single-cell suspension was prepared in PBS containing $0.01 \%$ sodium azide and $1 \%$ FCS. Each staining step was performed at $4{ }^{\circ} \mathrm{C}$ for 30 minutes. Phenotypic HSPCs were identified by staining with FITC-conjugated antibodies indicating the lineage-positive phenotype (anti-CD4, NK, CD8, B220, $\mathrm{CD} 11 \mathrm{~b}$, and GR-1), the PE-conjugated/PE-Cy7-conjugated anti-Sca-1 and APC-conjugated anti-cKit antibodies (all from Biolegend), and the eFlour 450-conjugated anti-CD34 antibody (eBioscience). Additional primary antibodies were: PE-conjugated anti-CD45.1 and FITC-conjugated antiCD45.2 (eBioscience); rabbit anti-CXCR4 (Torrey Pines Biolabs); rabbit anti-GSK3 (R\&D Systems); rabbit anti-phospho-Ser9-GSK3 $\beta$ (Cell Signaling); mouse anti-phospho-Tyr216-GSK3 $\beta$ (BD), and mouse anti-acetylated tubulin (Sigma-Aldrich). Secondary antibodies were: minimally cross-reactive R-PE-conjugated donkey anti-rabbit and anti-mouse (Jackson ImmunoResearch). Rat anti-CD16/32 antibody (eBioscience) was used to block endogenous $\mathrm{Fc}_{\mathrm{c}}$ receptors when primary murine antibodies were used. In order to fix and permeabilize cells for intracellular staining following extracellular staining, the Cytofix/Cytoperm kit (BD) was used.

LTR assay. Repopulation was performed with whole blood from donor C57BL/6 (CD45.2) mice, which were treated with BIO-A or equivalent DMSO prior to sacrifice. Recipient B6.SJL (CD45.1) mice were lethally irradiated $(10 \mathrm{~Gy}) 24$ hours prior to transplantation. Each recipient mouse was i.v. injected with $500 \mu \mathrm{lPB}$ together with $2 \times 10^{5}$ host-type competitive 
total BM cells. Donor chimerism was assessed after 4 months using flow cytometry to detect the expression of CD45.1/CD45.2 congenic alleles.

Immunohistochemistry. Sterna were fixed (4\% paraformaldehyde in PBS for 24 hours), decalcified (10\% EDTA at $\mathrm{pH} 7.5$ for 7 to 10 days), and paraffin embedded. Bone sections underwent de-paraffinization, antigen retrieval, blocking with $10 \%$ horse serum (Vector Laboratories) and immune-labeled using $5 \mathrm{mg} / \mathrm{ml}$ goat anti-mouse SCF antibody (R\&D Systems). Immunoreactivity was detected using biotinylated goat-specific secondary antibody (Dako) followed by an LSAB2 avidin-biotin DAB detection kit (Dako) according to the manufacturer's instructions.

CFU assay. Murine PB MNCs $\left(2 \times 10^{5} / \mathrm{ml}\right)$ or BM MNCs $\left(10^{3} / \mathrm{ml}\right)$ were seeded for the progenitor colony assay as described (61). The cells were plated in $0.9 \%$ (wt/vol) methylcellulose (Sigma-Aldrich), 30\% (vol/vol) FCS (Gibco, Invitrogen), $50 \mathrm{ng} / \mathrm{ml}$ murine SCF (PeproTech), $5 \mathrm{ng} / \mathrm{ml}$ murine IL-3 (Kirin), $5 \mathrm{ng} / \mathrm{ml}$ murine granulocyte-macrophage CSF (GM-CSF; $\mathrm{R} \& \mathrm{D}$ Systems), and $2 \mathrm{U} / \mathrm{ml}$ erythropoietin (Janssen Biotech). Colonies were scored 7 days after plating according to morphological criteria.

Chemotaxis assay. Chemotaxis experiments were assayed using Costar Transwells (6.5 mm diameter, $5 \mu \mathrm{m}$ pore; Corning) as previously described (51). Murine BM MNCs or Lin- BM cells were treated with BIO-A as indicated above or with equivalent DMSO control for 1 hour prior to the chemotaxis assay. In indicated experiments, the cells were additionally treated with nocodazole or equivalent DMSO for 15 minutes. Alternatively, they were treated with $100 \mathrm{ng} / \mathrm{ml}$ mouse SCF (ProSpec), with or without BIO-A for 4 hours. The cells were then loaded onto Transwells $\left(2 \times 10^{5}\right.$ cells per well). Medium (RPMI supplemented with $10 \%$ FCS and $125 \mathrm{ng} / \mathrm{ml} \mathrm{CXCL12;} \mathrm{PeproTech)} \mathrm{was} \mathrm{placed} \mathrm{in} \mathrm{the} \mathrm{bottom} \mathrm{chamber.} \mathrm{Migra-}$ tion was allowed for 2 hours at $37^{\circ} \mathrm{C}$ and $5 \% \mathrm{CO}_{2}$. Migrating cells from the bottom chambers were applied for cell counting by FACSCalibur.

Chemotaxis assay of HSPCs. In order to evaluate HSPC migration toward CXCL12, media were collected from the bottom wells (duplicates per sample), some of which was taken to assess BM MNC/Lin- BM cell migration by flow cytometry as described above, and some of which was taken to measure HSPC percentage. Migrating HSPCs were measured by staining for $\mathrm{Lin}^{-} \mathrm{CKit}^{+}$cells or by performing CFU assays. Migrating phenotypic HSCs were measured by staining for $\mathrm{CD} 34-\mathrm{Lin}^{-} \mathrm{Sca}-1^{+} \mathrm{CKit}^{+}$cells. HSPCs were also measured among treated cells that were not subjected to chemotaxis assay for evaluation of the HSPC index prior to migration. Th migratory percentage of HSPCs $=\left(\%\right.$ BM MNCs or Lin ${ }^{-}$BM cell migration $) \times(\%$ HSPCs among migrating BM MNCs or Lin $^{-}$BM cells)/(\% HSPCs among BM MNCs or Lin- BM cells prior to migration).

Immunofluorescence staining for microscope. Cells were immunostained in a similar fashion to that of flow cytometry, however, they were first fixed with $2 \%$ PFA for 20 minutes. Cells were permeabilized using the Cytofix/ Cytoperm kit (BD) and then stained for intracellular antigens. In the final step, Hoechst 33342 Molecular Probes (Invitrogen) were used for nuclear staining. Immunostained cells were placed on coverslips previously coated with polylysine (Sigma-Aldrich) and then mounted on slides using immunomount medium (Thermo Scientific). Immunofluorescence images were acquired using an Olympus BX51 fluorescence microscope and an Olympus DP71 camera. Images were processed using ImageJ 1.44 software (NIH) and Adobe Photoshop CS5 (Adobe Systems).

CXCL12-induced actin polymerization and polarization. BM MNCs or isolated $\mathrm{Lin}^{-} / \mathrm{CKit}^{+} \mathrm{BM}$ cells were treated or not with BIO-A for 1 hour and then stimulated or not with $200 \mathrm{ng} / \mathrm{ml} \mathrm{CXCL12} \mathrm{(PeproTech)} \mathrm{for} 30 \mathrm{sec}-$ onds (to examine polymerization) or for 5 minutes (to examine polarization), while kept at $37^{\circ} \mathrm{C}$ in a thermo block. The cells were immediately fixed and either stained or not for additional markers (CD34, Lin markers, Sca-1, cKit) as indicated in the immunofluorescence methodology. Phalloidin-FITC ( $1 \mu \mathrm{g} / \mathrm{ml}$; Sigma-Aldrich) was used to bind and stain for F-actin. CXCL12-induced actin polymerization was measured using the FACSCalibur and calculated as the difference in F-actin content between CXCL12-stimulated and nonstimulated cells. Polarization and formation of cell and actin protrusions were observed by fluorescence microscopy as described in the immunofluorescence methodology or by ImageStream, as described below.

ImageStream analysis. Isolated Lin- BM cells that underwent actin polarization assay as indicated above were collected with the ImageStreamX (Amnis). Samples were visualized and analyzed for the expression of markers and proteins with IDEAS 4.0 software (Amnis) (62). Single-stained control cells were used to compensate for fluorescence intensity between channel images. Cells were gated for single cells, with the area and aspect ratio features, and for focused cells, with the gradient RMS features, as described previously (62). Further gating was performed for the selection of phalloidin-FITC-expressing cells and target subpopulations, such as CD34-Lin-S$\mathrm{ca}-1^{+} \mathrm{CKit}{ }^{+}$cells, according to the pixel intensity of the different markers. Polarized versus nonpolarized cells were evaluated among the gated cells.

Homing assay of hematopoietic progenitor cells. NOD/SCID mice were lethally irradiated ( $6 \mathrm{~Gy}) 24$ hours prior to transplantation in order to diminish host CFU cells. BM MNCs were treated in vitro or obtained from in vivotreated mice and then transplanted $\left(5 \times 10^{6}\right.$ cells per mouse) into the recipient NOD/SCID mice. Sixteen hours after injection, BM cells were harvested from femurs and seeded into semisolid cultures to identify CFU cells, as described above. Donor CFU cells were equivalent to approximately $95 \%$ of the cultured CFU cells. Homing of hematopoietic progenitor cells is calculated as CFU cells per femur.

Statistics. Significance levels of the data were determined by 2 -tailed Student's $t$ tests using Microsoft Excel 2007. $P$ values less than 0.05 were considered significant. Error bars represent standard error of the mean.

Study approval. The Animal Care and Use Committee of the Weizmann Institute of Science approved all animal experiments.

\section{Acknowledgments}

We thank Amir Schajnovitz for technical assistance. This study was supported in part by the Israeli Science Foundation (544/09), the European Union (Advance Cell-based Therapies for the Treatment of Primary Immunodeficiency, HEALTH-F5-2010-261387), the European Commission (CELLPID FP7-261387), and the Leona M. and Harry B. Helmsley Charitable Trust.

Received for publication April 3, 2012, and accepted in revised form January 14, 2013.

Address correspondence to: Tsvee Lapidot, Immunology Department, Weizmann Institute of Science, P.O. Box 26, Rehovot 76100, Israel. Phone: 972.89342481; Fax: 972.89344141; E-mail: tsvee.lapidot@weizmann.ac.il.
1. Laird DJ, von Andrian UH, Wagers AJ. Stem cell trafficking in tissue development, growth, and disease. Cell. 2008;132(4):612-630.

2. Lapid K, Vagima Y, Kollet O, Lapidot T. Egress and Mobilization of Hematopoietic Progenitor Cells. Cambridge, Massachusetts, USA: StemBook, Harvard Stem Cell Institute; 2009.
3. Trowbridge JJ, Xenocostas A, Moon RT, Bhatia M. Glycogen synthase kinase- 3 is an in vivo regulator of hematopoietic stem cell repopulation. Nat Med. 2006;12(1):89-98.

4. Holmes T, et al. Glycogen synthase kinase-3beta inhibition preserves hematopoietic stem cell activity and inhibits leukemic cell growth. Stem Cells.
2008;26(5):1288-1297.

5. Huang J, et al. Pivotal role for glycogen synthase kinase-3 in hematopoietic stem cell homeostasis in mice. J Clin Invest. 2009;119(12):3519-3529.

6. Ko KH, et al. GSK-3beta inhibition promotes engraftment of ex vivo-expanded hematopoietic stem cells and modulates gene expression. Stem 
Cells. 2011;29(1):108-118.

7. Zhao C, et al. Loss of beta-catenin impairs the renewal of normal and CML stem cells in vivo. Cancer Cell. 2007;12(6):528-541.

8. Scheller M, et al. Hematopoietic stem cell and multilineage defects generated by constitutive beta-catenin activation. Nat Immunol. 2006;7(10):1037-1047.

9. Kirstetter P, Anderson K, Porse BT, Jacobsen SE, Nerlov C. Activation of the canonical Wnt pathway leads to loss of hematopoietic stem cell repopulation and multilineage differentiation block. Nat Immunol. 2006;7(10):1048-1056.

10. Goessling W, et al. Genetic interaction of PGE2 and Wnt signaling regulates developmental specification of stem cells and regeneration. Cell. 2009;136(6):1136-1147.

11. Fleming HE, et al. Wnt signaling in the niche enforces hematopoietic stem cell quiescence and is necessary to preserve self-renewal in vivo. Cell Stem Cell. 2008;2(3):274-283.

12. Sun T, Rodriguez M, Kim L. Glycogen synthase kinase 3 in the world of cell migration. Dev Growth Differ. 2009;51(9):735-742.

13. Yuskaitis CJ, Jope RS. Glycogen synthase kinase-3 regulates microglial migration, inflammation, and inflammation-induced neurotoxicity. Cell Signal. 2009;21(2):264-273.

14. Wu X, et al. Skin stem cells orchestrate directional migration by regulating microtubule-ACF7 connections through GSK33. Cell. 2011;144(3):341-352.

15. Kobayashi T, et al. Glycogen synthase kinase 3 and h-prune regulate cell migration by modulating focal adhesions. Mol Cell Biol. 2006;26(3):898-911.

16. Rådinger M, Kuehn HS, Kim MS, Metcalfe DD, Gilfillan AM. Glycogen synthase kinase 3beta activation is a prerequisite signal for cytokine production and chemotaxis in human mast cells. J Immunol. 2010;184(2):564-572.

17. Wright DE, Wagers AJ, Gulati AP, Johnson FL, Weissman IL. Physiological migration of hematopoietic stem and progenitor cells. Science. 2001;294(5548):1933-1936.

18. Peled A, et al. Dependence of human stem cell engraftment and repopulation of NOD/SCID mice on CXCR4. Science. 1999;283(5403):845-848.

19. Sugiyama T, Kohara H, Noda M, Nagasawa T. Maintenance of the hematopoietic stem cell pool by CXCL12-CXCR4 chemokine signaling in bone marrow stromal cell niches. Immunity. 2006;25(6):977-988.

20. Tzeng YS, Li H, Kang YL, Chen WC, Cheng WC, Lai DM. Loss of Cxcl12/Sdf-1 in adult mice decreases the quiescent state of hematopoietic stem/progenitor cells and alters the pattern of hematopoietic regeneration after myelosuppression. Blood. 2011;117(2):429-439.

21. Voermans C, Kooi ML, Rodenhuis S, van der Lelie $\mathrm{H}$, van der Schoot CE, Gerritsen WR. In vitro migratory capacity of CD34+ cells is related to hematopoietic recovery after autologous stem cell transplantation. Blood. 2001;97(3):799-804.

22. Méndez-Ferrer S, Lucas D, Battista M, Frenette PS. Haematopoietic stem cell release is regulated by circadian oscillations. Nature. 2008;452(7186):442-447.

23. Broxmeyer HE, et al. Rapid mobilization of murine and human hematopoietic stem and progenitor cells with AMD3100, a CXCR4 antagonist. J Exp Med. 2005;201(8):1307-1318.

24. Dar A, et al. Rapid mobilization of hematopoietic progenitors by AMD3100 and catecholamines is mediated by CXCR4-dependent SDF-1 release from bone marrow stromal cells. Lenkemia. 2011;25(8):1286-1296.

25. Spiegel A, et al. Catecholaminergic neurotransmitters regulate migration and repopulation of immature human $\mathrm{CD}^{+} 4^{+}$cells through Wnt signaling. Nat Immunol. 2007;8(10):1123-1131.

26. Cheng $M$, et al. CXCR4-mediated bone mar- row progenitor cell maintenance and mobilization are modulated by c-kit activity. Circ Res. 2010;107(9):1083-1093.

27. Kimura Y, Ding B, Imai N, Nolan DJ, Butler JM, Rafii S. c-Kit-mediated functional positioning of stem cells to their niches is essential for maintenance and regeneration of adult hematopoiesis. PLoS One. 2011;6(10):e26918.

28. Dutt P, Wang JF, Groopman JE. Stromal cell-derived factor-1 alpha and stem cell factor/kit ligand share signaling pathways in hemopoietic progenitors: a potential mechanism for cooperative induction of chemotaxis. J Immunol. 1998;161(7):3652-3658.

29. Kim CH, Broxmeyer HE. In vitro behavior of hematopoietic progenitor cells under the influence of chemoattractants: stromal cell-derived factor-1, steel factor, and the bone marrow environment. Blood. 1998;91(1):100-110.

30. Bonig H, Priestley GV, Papayannopoulou T. Hierarchy of molecular-pathway usage in bone marrow homing and its shift by cytokines. Blood. 2006;107(1):79-86.

31. Welniak LA, Karas M, Yakar S, Anver MR, Murphy WJ, LeRoith D. Effects of organ-specific loss of insulin-like growth factor-I production on murine hematopoiesis. Biol Blood Marrow Transplant. 2004;10(1):32-39.

32. Ogawa M, et al. Expression and function of c-kit in hemopoietic progenitor cells. J Exp Med. 1991;174(1):63-71.

33. Kent D, Copley M, Benz C, Dykstra B, Bowie M, Eaves C. Regulation of hematopoietic stem cells by the steel factor/KIT signaling pathway. Clin Cancer Res. 2008;14(7):1926-1930.

34. Tsarfaty G, Longo DL, Murphy WJ. Human insulin-like growth factor I exerts hematopoietic growth-promoting effects after in vivo administration. Exp Hematol. 1994;22(13):1273-1277.

35. Ding L, Saunders TL, Enikolopov G, Morrison SJ. Endothelial and perivascular cells maintain haematopoietic stem cells. Nature. 2012;481(7382):457-462.

36. Voermans C, Anthony EC, Mul E, van der Schoot E, Hordijk P. SDF-1-induced actin polymerization and migration in human hematopoietic progenitor cells. Exp Hematol. 2001;29(12):1456-1464.

37. Wang JF, Park IW, Groopman JE. Stromal cell-derived factor-1alpha stimulates tyrosine phosphorylation of multiple focal adhesion proteins and induces migration of hematopoietic progenitor cells: roles of phosphoinositide-3 kinase and protein kinase C. Blood. 2000;95(8):2505-2513

38. Zhang XF, Wang JF, Matczak E, Proper JA, Groopman JE. Janus kinase 2 is involved in stromal cell-derived factor-1alpha-induced tyrosine phosphorylation of focal adhesion proteins and migration of hematopoietic progenitor cells. Blood. 2001;97(11):3342-3348.

39. Fonseca AV, Freund D, Bornhäuser M, Corbeil D. Polarization and migration of hematopoietic stem and progenitor cells rely on the RhoA/ROCK I pathway and an active reorganization of the microtubule network. J Biol Chem. 2010;285(41):31661-31671.

40. Lucas D, Battista M, Shi PA, Isola L, Frenette PS Mobilized hematopoietic stem cell yield depends on species-specific circadian timing. Cell Stem Cell. 2008;3(4):364-366

41. Méndez-Ferrer S, Battista M, Frenette PS. Cooperation of beta(2)- and beta(3)-adrenergic receptors in hematopoietic progenitor cell mobilization. Ann NY Acad Sci. 2010;1192:139-144.

42. Katayama Y, et al. Signals from the sympathetic nervous system regulate hematopoietic stem cell egress from bone marrow. Cell. 2006;124(2):407-421.

43. Urbanska K, et al. Inhibition of IGF-I receptor in anchorage-independence attenuates GSK-3beta constitutive phosphorylation and compromises growth and survival of medulloblastoma cell lines. Oncogene. 2007;26(16):2308-2317.
44. Haider HKh, Jiang S, Idris NM, Ashraf M. IGF-1-overexpressing mesenchymal stem cells accelerate bone marrow stem cell mobilization via paracrine activation of SDF-1alpha/CXCR4 signaling to promote myocardial repair. Circ Res. 2008;103(11):1300-1308.

45. Webster DR, Borisy GG. Microtubules are acetylated in domains that turn over slowly. J Cell Sci. 1998;92(pt 1):57-65.

46. Mendez-Ferrer S, Frenette PS. Hematopoietic stem cell trafficking: regulated adhesion and attraction to bone marrow microenvironment. Ann N Y Acad Sci. 2007;1116:392-413.

47. Golan K, et al. S1P promotes murine progenitor cell egress and mobilization via S1P1-mediated ROS signaling and SDF-1 release. Blood. 2012;119(11):2478-2488.

48. Mendez-Ferrer S, Chow A, Merad M, Frenette PS. Circadian rhythms influence hematopoietic stem cells. Curr Opin Hematol. 2009;16(4):235-242.

49. Ehninger A, Boch T, Essers M, Laurenti E, Trumpp A. Regulation of c-Myc expression in adult hematopoietic stem cells during homeostasis and stress. ISEH 41st Annual Scientific Meeting/Experimental Hematology. 2012;40:S114.

50. Kassmer SH, Niggemann B, Punzel M, Mieck C, Zänker KS, Dittmar T. Cytokine combinations differentially influence the SDF-1alpha-dependent migratory activity of cultivated murine hematopoietic stem and progenitor cells. Biol Chem. 2008;389(7):863-872.

51. Kollet O, et al. Rapid and efficient homing of human CD34(+)CD38(-/low)CXCR4(+) stem and progenitor cells to the bone marrow and spleen of NOD/SCID and NOD/SCID/B2m(null) mice. Blood. 2001;97(10):3283-3291.

52. Bertrand FE, et al. Synergy between an IGF-1R antibody and Raf/MEK/ERK and PI3K/Akt/ mTOR pathway inhibitors in suppressing IGF-1Rmediated growth in hematopoietic cells. Lenkemia. 2006;20(7):1254-1260.

53. Wysoczynski M, et al. Incorporation of CXCR4 into membrane lipid rafts primes homing-related responses of hematopoietic stem/progenitor cells to an SDF-1 gradient. Blood. 2005;105(1):40-48.

54. Etienne-Manneville S, Hall A. Cdc42 regulates GSK-3beta and adenomatous polyposis coli to control cell polarity. Nature. 2003;421(6924):753-756.

55. Nie Y, Han YC, Zou YR. CXCR4 is required for the quiescence of primitive hematopoietic cells. J Exp Med. 2008;205(4):777-783.

56. Yang L, Wang L, Geiger H, Cancelas JA, Mo J, Zheng Y. Rho GTPase Cdc42 coordinates hematopoietic stem cell quiescence and niche interaction in the bone marrow. Proc Natl Acad Sci U S A. 2007;104(12):5091-5096.

57. Gu Y, et al. Hematopoietic cell regulation by Rac1 and Rac2 guanosine triphosphatases. Science. 2003;302(5644):445-449.

58. Itkin T, et al. FGF-2 expands murine hematopoietic stem and progenitor cells via proliferation of stromal cells, c-Kit activation, and CXCL12 down-regulation. Blood. 2012;120(9):1843-1855.

59. Yeoh JS, et al. Fibroblast growth factor-1 and -2 preserve long-term repopulating ability of hematopoietic stem cells in serum-free cultures. Stem Cells. 2006;24(6):1564-1572.

60. Frostad S, Bjerknes R, Abrahamsen JF, Olweus J, Bruserud O. Insulin-like growth factor-1 (IGF-1) has a costimulatory effect on proliferation of committed progenitors derived from human umbilical cord CD34+ cells. Stem Cells. 1998;16(5):334-342.

61. Petit I, et al. G-CSF induces stem cell mobilization by decreasing bone marrow SDF-1 and up-regulating CXCR4. Nat Immunol. 2002;3(7):687-694.

62. Ludin A, et al. Monocytes-macrophages that express alpha-smooth muscle actin preserve primitive hematopoietic cells in the bone marrow. Nat Immunol. 2012;13(11):1072-1082. 